\title{
Protection induced by a human monoclonal antibody recognizing two different epitopes in a conserved region of streptococcal $M$ proteins
}

\author{
Wael Bahnan $^{\mathrm{a}}$, Lotta Happonen ${ }^{\mathrm{a}}$, Hamed Khakzad ${ }^{\mathrm{b}, \mathrm{c}}$, Vibha Kumra Ahnlide ${ }^{\mathrm{a}}$, Therese de Neergaard ${ }^{\mathrm{a}}$, Sebastian Wrighton ${ }^{\mathrm{a}}$, \\ Eleni Bratanis ${ }^{\mathrm{a}}$, Di Tang ${ }^{\mathrm{a}}$, Thomas Hellmark ${ }^{\mathrm{d}}$, Lars Björck ${ }^{\mathrm{a}}$, Oonagh Shannon ${ }^{\mathrm{a}}$, Lars Malmström ${ }^{\mathrm{a}, \mathrm{e}}$, Johan Malmström ${ }^{\mathrm{a}}$, and \\ Pontus Nordenfelt ${ }^{\mathrm{a} 冈}$

\begin{abstract}
a'Lund University, Faculty of Medicine, Department of Clinical Sciences Lund, Infection Medicine, SE-22184 Lund, Sweden. ${ }^{b}$ Equipe Signalisation Calcique et Infections Microbiennes, Ecole Normale Superieure Paris-Saclay, 91190 Gif-sur-Yvette, France. 'Institut National de la Sante et de la Recherche Medicale (INSERM) U1282, 91190 Gif-sur-Yvette, France. dd Lund University, Skane University Hospital, Department of Clinical Sciences Lund, Nephrology, Lund, Sweden. ${ }^{e}$ e Institute for Computational Science, University of Zurich, Winterthurerstrasse 190, CH-8057 Zurich, Switzerland.
\end{abstract}

\begin{abstract}
Group A streptococci have evolved multiple strategies to evade human antibodies, making it challenging to create effective vaccines or antibody treatments. Here, we have generated antibodies derived from the memory $B$ cells of an individual who had successfully cleared a group A streptococcal infection. The antibodies bind with high affinity to the central region on the surface-bound $M$ protein. One antibody could effectively promote vital immune functions, including phagocytosis and in vivo protection. Remarkably, this antibody only interacts through dual-Fab cis mode, where the Fabs bind to two distinct epitopes in $M$ protein, and with conserved binding across strains. In contrast, another antibody binding to a single epitope in the same region does not bypass the $M$ protein's virulent effects. A broadly-binding, protective monoclonal antibody is a strong candidate for anti-streptococcal therapy. It also highlights the concept of dual-Fab binding and the accessibility of conserved regions for immune antibody targeting.
\end{abstract}

group A streptococci | M protein | antibody binding | dual-Fab binding | antibody function | structural mass spectrometry | phagocytosis | in vivo model

Correspondence: pontus.nordenfelt@med.lu.se

\section{Introduction}

Antibodies are essential components of the immune system used to recognize and neutralize external intruders such as pathogenic bacteria. They are produced by B cells after their B cell receptor reacts with a specific antigen in the lymphoid tissue. B cell maturation and antibody responses have evolved to allow for an extraordinary variety enabling the binding of most foreign antigens. $\mathrm{V}(\mathrm{D}) \mathrm{J}$ recombination events, as well as somatic hypermutation, give rise to a vast repertoire of antibody variable domains (1, 2). B cell activation, clonal expansion, maturation, and class switching result in the generation of IgG antibodies that offer long term protection against infectious agents (3).

An IgG antibody is a Y-shaped molecule composed of two identical Fab fragments and one $\mathrm{Fc}$ domain, where the unique binding specificity is mediated via the Fab interaction. IgG typically binds the antigen with either one of the two Fabs. The two Fabs can bind to two copies of the same antigen to increase binding strength through avidity, a process that is dependent on the antigen density and organization (4). We designate this latter form of binding as dual-Fab trans binding. When bound to their target, IgG molecules carry out effector functions by triggering clustering of $\mathrm{Fc}$ receptors on immune cells (5), which induces cell signaling and leads to a variety of downstream effects such as phagocytosis, immune recognition, and activation (6).

Group A streptococcus (GAS) is a common human pathogen causing significant morbidity and mortality in the human population and is an important causative agent of severe invasive infections (7, 8). The bacterium has evolved an extensive array of measures to counteract the human immune response (9), including resistance to phagocytosis (10, 11), and several immunoglobulin-targeting mechanisms (IdeS (12), EndoS (13), protein M/H (14)). The streptococcal M protein, a virulence determinant, has a long coiled-coiled structure with different regions (A, B, S, C, and D). These regions are typically associated with distinct protein interactions and bind many components of the humoral immune response (15, 16) such as $\mathrm{C} 4 \mathrm{BP}$ and factor $\mathrm{H}$, and forms complexes with fibrinogen (17) that can induce vascular leakage (18) and contribute to phagocytosis resistance $(19,20)$. The $M$ protein can also reduce phagocytosis by reversing the orientation of $\mathrm{IgG}$ by capturing IgG Fc domains $((14,21)$. These pathogenic mechanisms deprive the immune system of crucial defenses, allowing GAS to disseminate within a host and across the population.

Although GAS infections generate a humoral immune response, repeated exposures seem to be required to generate protective memory B cell immunity (22). There are few candidates for anti-bacterial monoclonal antibody therapy in general (23), and none available for GAS. Much effort has been allocated to developing vaccines against GAS (24), with the prime immunizing antigen being $M$ protein, particularly with M protein-based peptides (25). Yet, no effective vaccine against GAS has been approved to date. It is unclear what makes it so difficult to generate immunity, 
Figure 1

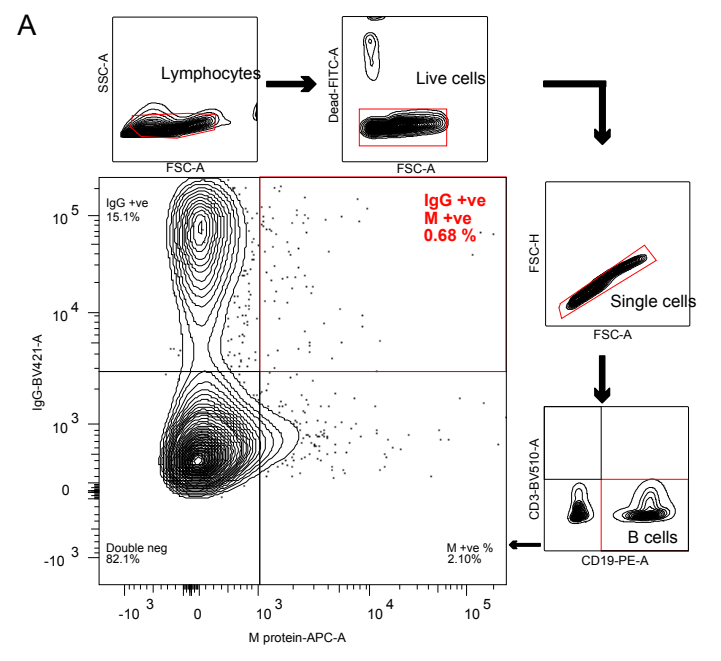

B
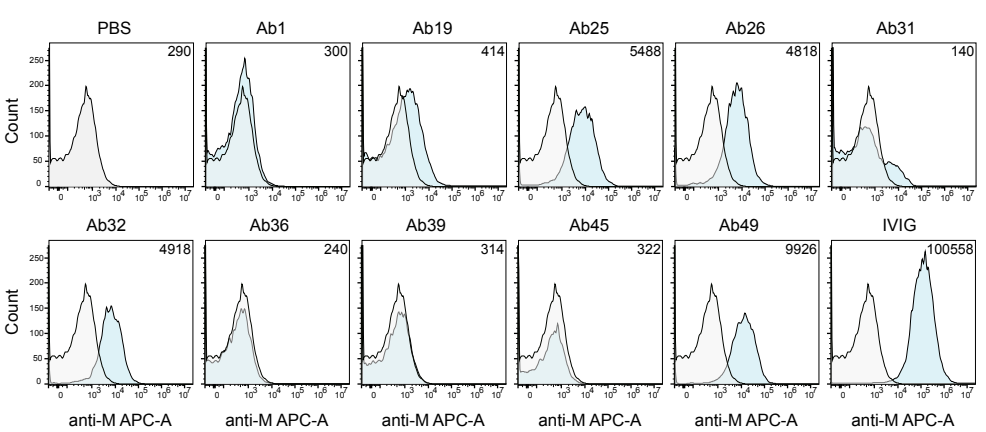

C
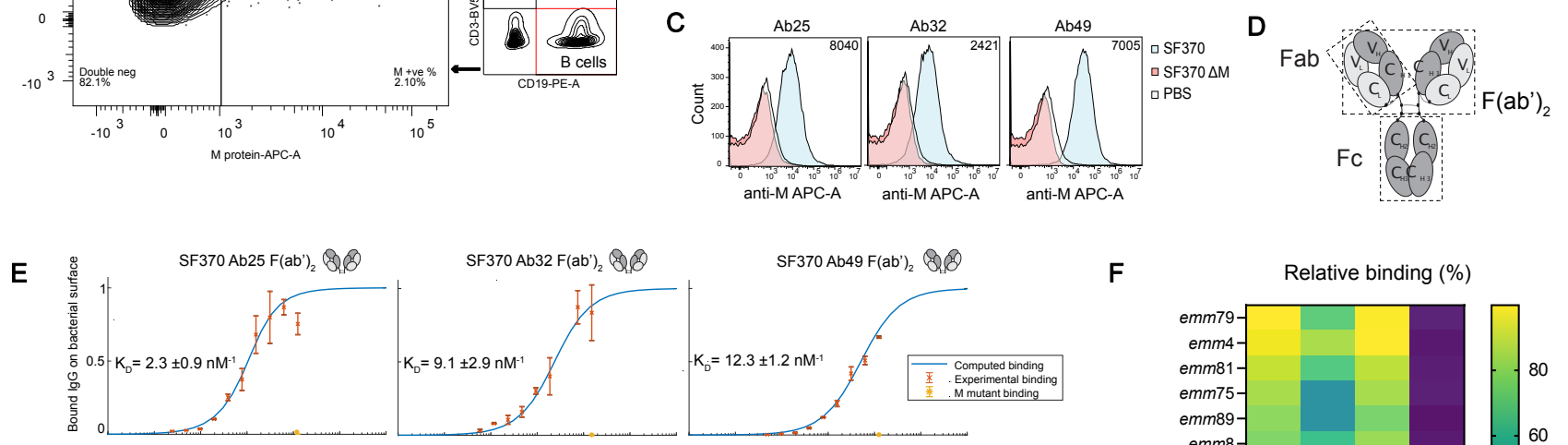

$\mathrm{F}$

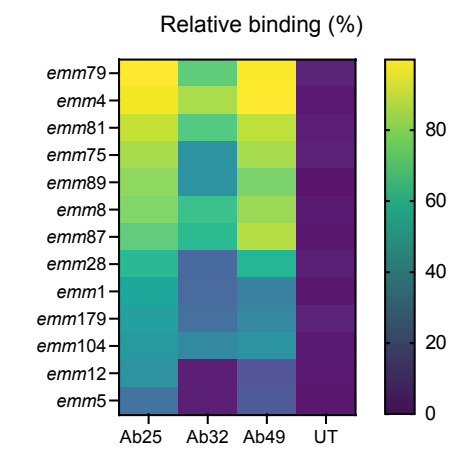

Fig. 1. Antigen-baiting allows the development of human single cell-derived M-specific antibodies. A B cells were isolated using Rosettesep B and were FACS sorted into single lymphocytes which were live (Syto9-FITC negative), expressing CD19 (PE), lacking CD3 (BV510) and which were dually positive for lgG and M protein (BV410 and AF647, respectively). B SF370 (GFP-transformed) bacteria were stained with the shown antibody and a secondary Fab anti-Fab antibody (conjugated to AF647) was used to generate the signal for flow cytometric analysis. The number in the upper right corner of the flow histograms indicates the median fluorescence intensity. $\mathbf{C}$ The specificity of the successful antibodies was assessed by comparing the staining of WT SF370 and $\Delta \mathrm{M}$ SF370. The bacteria were stained as in (B) with the aforementioned antibodies and were analyzed by flow cytometry. D A schematic representation of an IgG antibody. E Binding curves of antibodies to SF370 give estimate of affinity to M-protein. The affinity of the specific antibodies is approximately 250-1500 times higher than that of IgGFc binding to M-protein. Each plot here shows the measured binding (red error bars) of specific antibody to mid-log grown SF370 or the M mutant as a function of the total antibody concentration, together with a fitted binding curve using least squares method (blue curve). The bottom three plots are controls with a non-specific antibody that have been normalized according to the fitting of the bottom left binding curve, making the binding comparable across the three controls. $\mathrm{K}_{D}$ values for the fitting are given in each plot, together with a confidence interval calculated using the Bootstrap method. The binding was measured using flow cytometry. The antibodies (antibody fragments) used are shown in the top-right side of each graph. The plots show no binding of the specific antibodies to the $\mathrm{M}$ mutant (orange error bar) at the highest measured total antibody concentration. F Different M serotypes of GAS were heat killed and then prepared as in (B) and tested for reactivity against IdeS-cleaved Ab25, 32, 49 or untreated (UT, only secondary). The bacteria were analyzed by flow cytometry and the data was presented as a heat map. The displayed data is the combined result of three or more independent experiments.

but potentially formation of antibody subsets is suppressed by immunodominant regions (26) or the presence of cryptic epitopes (27). In severe life-threatening invasive GAS infections, intravenous IgG antibodies (IVIG) from human pooled plasma have been used as therapy, even though reports on their efficacy show contradictory results $(28,29,30,31)$. In the virus field it is well-established that certain antibodies have strong neutralizing abilities depending on epitope, binding angle, and glycan composition (32). So far, few studies have investigated the properties that constitute a protective antigen-specific antibody response against GAS.

Here, we have generated anti-M protein antibodies, derived from a healthy donor who had previously undergone a
GAS infection. When exposed to GAS and M protein, the antibodies bind and exert various effects, and we identify a new type of interaction where the two identical Fabs of one of the monoclonal IgG antibodies simultaneously bind to two distinct epitopes. We designate this form of binding as dual-Fab cis binding. Importantly, this broadly-binding antibody efficiently promoted all types of studied protective immune functions, including bacterial agglutination, NFkB activation, phagocytosis, and in vivo protection.

\section{Results}

Antigen-baiting allows the development of human single-cell derived M-specific antibodies. To under- 
stand what constitutes a protective antibody towards GAS infection, we generated functional human antibodies and analyzed their effects on virulence. We choose $\mathrm{M}$ protein as a target antigen, with a donor that had successfully cleared a streptococcal infection as a source of $\mathrm{M}$ protein-specific antibodies. To identify human antibodies with specificity towards streptococcal $\mathrm{M}$ protein, we isolated $\mathrm{CD} 19^{+} \mathrm{CD}^{-}$ $\mathrm{IgG}^{+} \mathrm{M}^{+} \mathrm{B}$ cells by baiting donor B cells with fluorescently conjugated M protein (Fig. 1A). The M protein we used is derived from an M1 serotype strain. We opted to use an M1 protein without knowing what serotype infected the original patient in order to increase the likelihood of identifying cross-strain reactive antibodies. Cloning RT-PCR of the variable regions of the heavy and light chains yielded ten antibody pairs (Supp. Fig. 1A). SDS-PAGE and mass spectrometry analysis of the antibodies expressed in HEK293 showed correct expression of the intact antibodies (Supp. Fig. 1B). Several antibodies showed clear reactivity to surface-bound M1 protein on GAS (strain SF370), the most common M protein among GAS isolates (Fig. 1B).

Further experiments with three selected antibodies using a $\triangle$ MM SF370 mutant strain lacking the M1 protein, demonstrated that binding of Ab25, 32, and 49 to the streptococcal surface was $M$ protein-dependent (Fig. 1C). We could confirm that all three antibodies could be found in the donor serum through mass spectrometric analysis of proteotypic peptides. We measured the antibody binding affinities to the surface of SF370 with either intact antibodies or F(ab') $)_{2}$ fragments (Fig. 1D), the latter to avoid contribution from M1's binding to IgGFc (Åkesson et al., 1994). Intact Xolair (Omalizumab, anti-IgE) showed a $\mathrm{K}_{D}$ of $\left(3.2 \times 10^{-6}\right.$ $\mathrm{M}^{-1}$ ), signifying a low binding affinity in concordance with previous reported $\mathrm{IgGF}$ affinity for purified M1 protein $\left(3.4 \times 10^{-6}\right)(14) . \mathrm{F}(\mathrm{ab})_{2}$ fragments of $\mathrm{Ab} 25,32$, and 49 had considerably higher affinities for M1;2.3× $10^{-9}, 9.1 \times 10^{-9}$, and $12.3 \times 10^{-9} \mathbf{M}^{-1}$, respectively (Fig. 1E). To assess the reactivity of $\mathrm{Ab} 25,32$ and 49 across different GAS M serotypes, we measured the binding of the antibodies to GAS emm serotypes 1, 4, 5, 8, 12, 28, 75, 79, 81, 87, 89, 104, and 179. We discovered that Ab25 and Ab49 have similar broad reactivity against these serotypes, with the strongest relative binding to emm 4 and emm 79 , and with lowest relative binding to emm5 (Fig. 1F). The cross-reactivity pattern was different for Ab32, including lack of binding to some strains.

Characterization of anti-M antibodies. To characterize the identified anti-M1 antibodies, we performed a panel of biochemical and immunological assays. We used structured illumination microscopy (SIM) immunofluorescence (IF) to visualize the anti-M binding pattern on the surface of SF370. Binding to the M protein shows a similar punctate distribution along the surface of the organism with all the monoclonal antibodies, including the $\mathrm{Fc}$-mediated Xolair binding (Fig. 2A). IVIG, which contains pooled IgG from thousands of donors, instead stained the whole surface of the bacteria indicating expected polyspecific coverage (Fig. 2A).
Ab25 showed the best reactivity with $M$ protein using an anti-M ELISA (Fig. 2B), whereas Ab32 showed the best binding to $M$ protein in Western blot (WB) experiments (Fig. 2C). Taken together, the data from IF, ELISA, and WB indicate that the three monoclonals have different modes of binding to the M1 protein.

Antibody-mediated bacterial agglutination is a welldocumented antibody function and has important biological significance such as enchaining bacteria for effective immune clearance (33, 34). Another well-known interbacterial, GAS-specific phenomenon is the formation of M-dependent bacterial aggregates at the bottom of the growth tube (35). While it is not possible to grow GAS without having any self-aggregation, the antibodies greatly enhanced bacterial agglutination. Both the triple antibody cocktail as well as individual antibodies led to dose-dependent agglutination, as is also the case with donor serum from the patient from which the M-reactive B cells were obtained (Fig. 2D, Supp. Fig. 2B). This enhancement was not observed for the $\Delta \mathrm{M}$ strain, further validating that the antibody-dependent agglutination is an M-specific phenomenon. Agglutinated bacteria, as well as the typical GAS aggregates, could be dissipated by vigorous vortexing in the presence of the anti-M antibodies or plasma (Supp. Fig. 2C). GAS agglutination and aggregate dissolution were most pronounced in Ab25, 49, and to a lesser extent with Ab32, while Xolair (with only IgGFc-binding) had no effect.

Through ligating their antigens and mediating antigen uptake, antibodies also activate macrophages leading to proinflammatory cytokine production (36). We addressed the antibody-dependent $M$ protein-induced immune activation using THP-1 X-Blue reporter cells, which secrete SEAP (secreted embryonic alkaline phosphatase) as a quantitative indicator of $\mathrm{NF} \varkappa \mathrm{B}$ activation. We found that $\mathrm{M}$ protein alone cannot induce NF-B signaling. However, combining $\mathrm{M}$ protein with $\mathrm{Ab} 25$ led to a significant 2.8-fold increase in $\mathrm{NF} \varkappa \mathrm{B}$ activation when compared to $\mathrm{M}$ protein with Xolair (Fig. 2E). Combining M protein with Ab49 had a modest effect on $\mathrm{NF} x \mathrm{~B}$ activation (1.6-fold, ns), whereas its combination with $\mathrm{Ab} 32$ had no impact (1.2-fold). Combining all three antibodies led to a significant cumulative 3.9-fold increase in $\mathrm{NF} \varkappa \mathrm{B}$ activation, probably due to the combined amount of Ab25 and 49. Interestingly, we also found that IVIG does not elicit the same antibody-mediated NFxB activation upon THP-1 exposure to the IVIG-treated M protein (1.4-fold). The combined biochemical and immunological characterization of the monoclonals shows that all are specific for $\mathrm{M}$ protein, bind to different epitopes, and can induce immunological effects, and that Ab25 has the most potent effect overall.

Anti-M antibody promotes efficient phagocytosis. Phagocytosis is a receptor-mediated process where prey are internalized into phagosomes, followed by their maturation into acidic, hostile compartments (37). To investigate the 
bioRxiv preprint doi: https://doi.org/10.1101/2021.03.01.433494; this version posted March 19, 2021. The copyright holder for this preprint (which was not certified by peer review) is the author/funder, who has granted bioRxiv a license to display the preprint in perpetuity. It is made available under aCC-BY-NC-ND 4.0 International license.

Figure 2

A SIM immunofluorescence
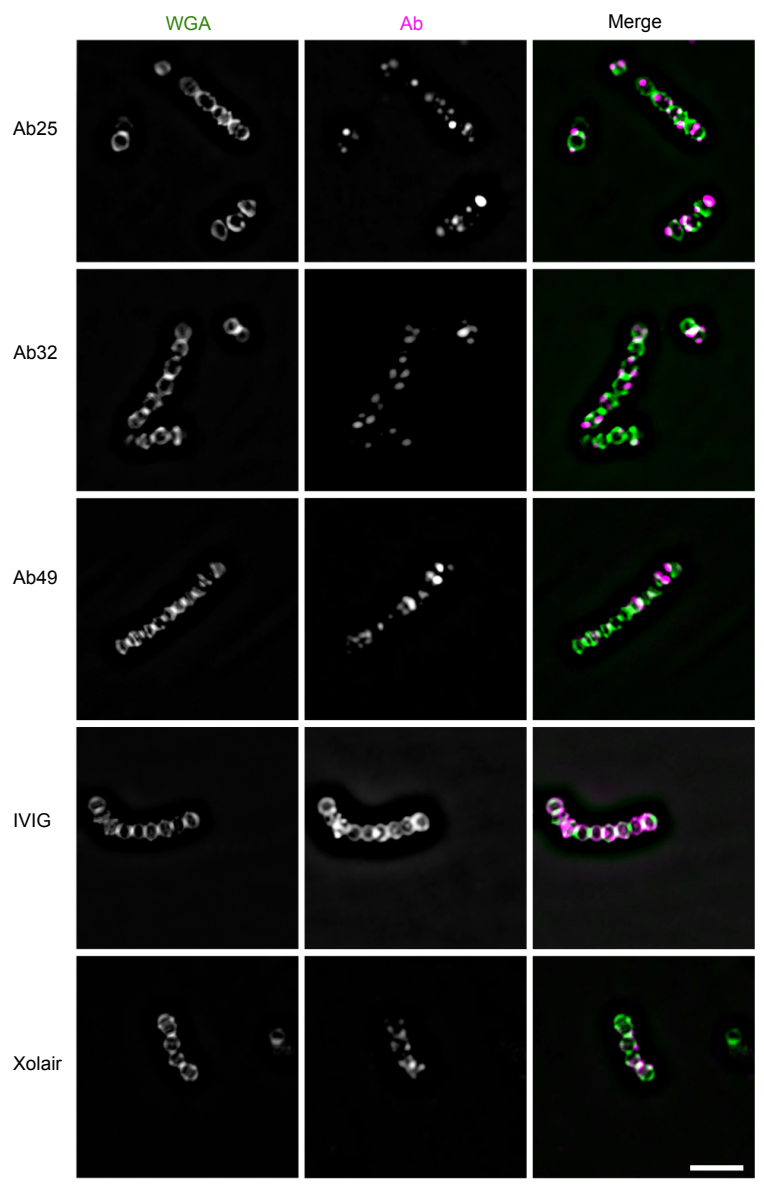

E NFkB activation

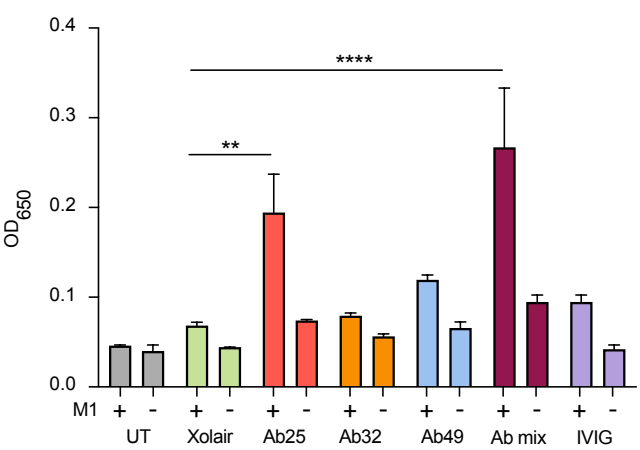

B ELISA

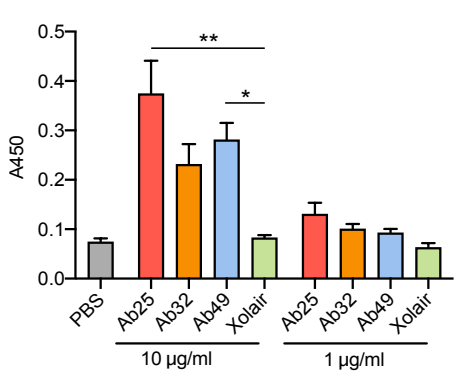

D Agglutination
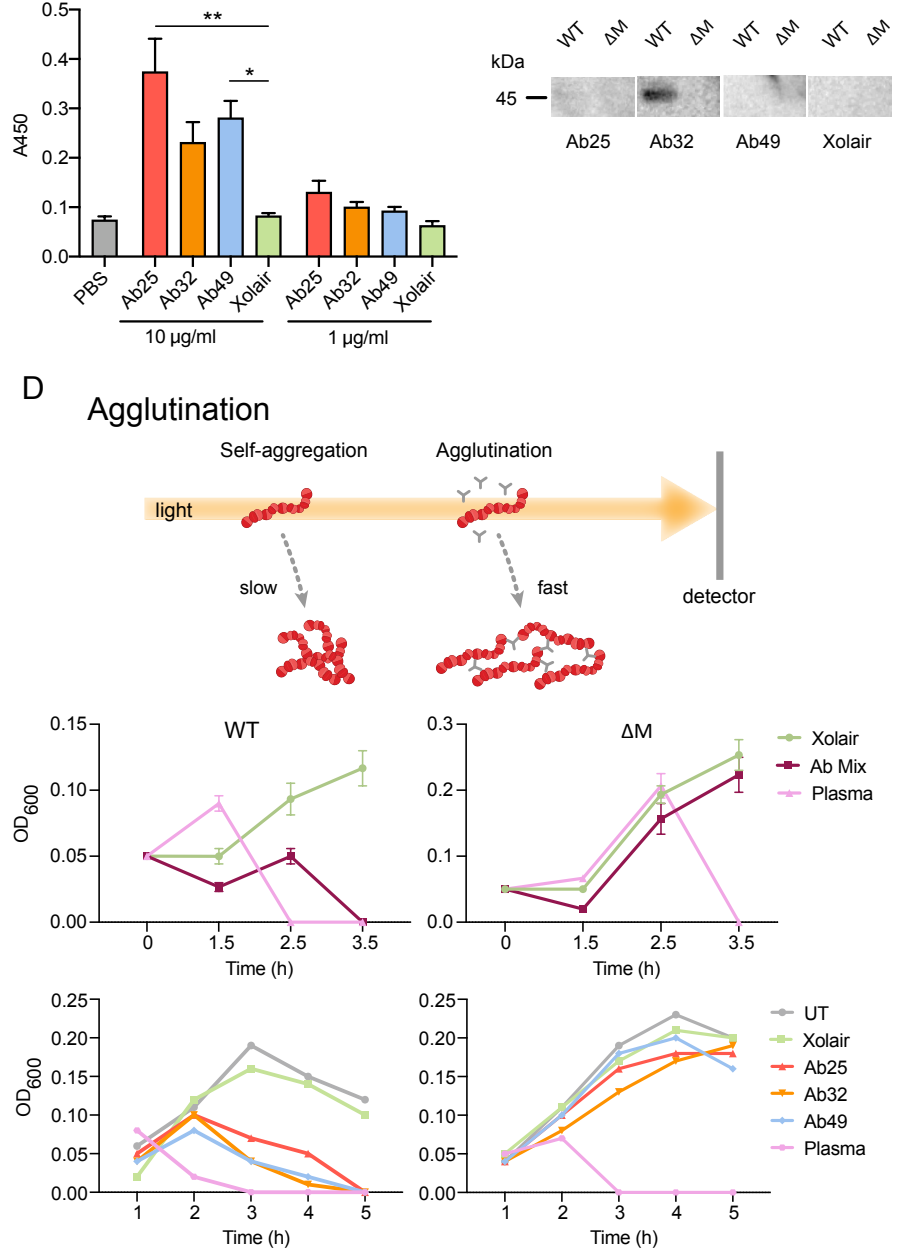

C Western blot 
cells (Fig. 3A). This can be seen as a left shift in the curve, meaning that fewer bacteria are required to achieve maximal association. When tested individually, only Ab25 showed increased association of bacteria to phagocytes, indicating that the antibody mix-mediated increase in association is solely due to Ab25 (Fig. 3B). The antibody mixture increased internalization when compared to Xolair, and the divergence between the two treatments was increased as a function of MOP (Fig. 3C). Upon a more detailed examination of individual antibodies, only Ab25 showed an increase in internalization (Fig. 3D). Dose-response analysis showed that Ab25 is significantly more effective than Xolair in mediating internalization (concentration at which 50\% of THP-1 cells have internalized bacteria; $\mathrm{EC}_{50} 0.8$ vs. $40.2 \mu \mathrm{g} / \mathrm{ml}$ ) (Fig. 3E). The phagocytosis data showed that despite strong Fab-mediated binding and induction of other immunological effects by all monoclonals, only one antibody, Ab25, can promote phagocytosis of group A streptococci. We have shown earlier (Fig. 1F) that Ab25 possesses broadly reacting potential against different $M$ types. For that reason, we tested its ability to opsonize and mediate the phagocytosis of non-M1 serotypes. Opsonization with Ab25 led to an increased phagocytic efficiency of the M1 (SF370 and AP1), M12, and M89 serotype strains, whereas the M5 was efficiently phagocytosed by THP-1 cells regardless if a binding opsonin was employed or not (Supp. Fig. 3B)

\section{Anti-M antibody protects mice from GAS infection.} The induction of phagocytosis and NF-B, as seen with Ab25, are important indicators of immune function. To test the potential protective effects of Ab25 in vivo, we used a mouse model of subcutaneous infection with GAS. We opted to only test Ab25 in our in vivo model since none of the other antibodies gave any indications of immune activity. The mice were pretreated with intraperitoneal injections of $\mathrm{Ab} 25$ or IVIG. High-dose IVIG have been used in mice models of severe GAS infections (39) and served as a positive control. Treatment with IVIG or Ab25 reduced the bacterial burden in the spleen, kidney, and liver when compared to untreated controls, with Ab25 exhibiting better protection than IVIG (Fig. 4A). Ab25 or IVIG treatment also reduced the cytokine mobilization of TNF $\alpha$, MCP-1, and IL-6 in plasma (Fig. 4B). The levels of IFN $\gamma$, IL-10 and IL-12p70 were below the level of detection under our experimental conditions. Taken together, the agglutination, NF-kB, phagocytosis, and animal experiments show that Ab25 has an immunomodulatory effect, which can protect an animal from GAS infection.

\section{Structural epitope characterization reveals dual-Fab} cis binding mode of interaction. Antibodies that bind via their Fabs with high affinity are typically expected to promote an immune response. However, only Ab25 promoted all of the tested immune effector functions. To assess structural differences and their mode of binding, we performed targeted cross-linking coupled to mass spectrometry (TX-MS) (40) of the M-protein and the antibodies.
Figure 3
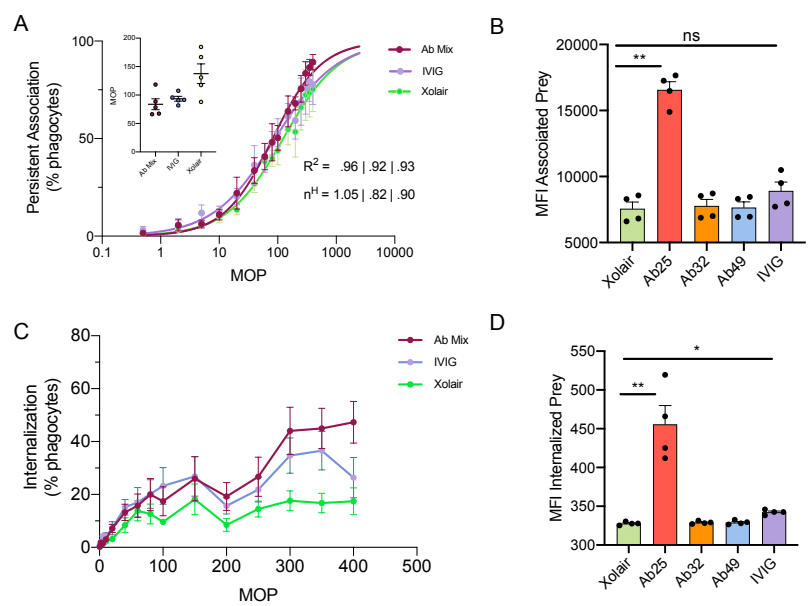

E

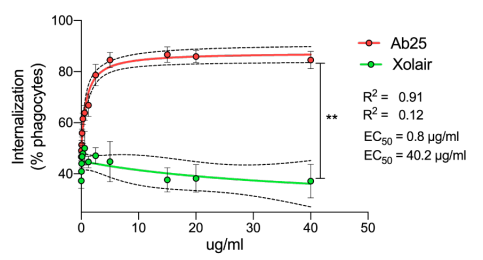

Fig. 3. Anti-M antibody promotes efficient phagocytosis. A THP-1 cells were incubated with increasing MOPs of heat killed SF370 bacteria (opsonized with 10 $\mu \mathrm{g} / \mathrm{ml}$ Xolair, anti-M antibody mix or IVIG). The THP-1 cells were allowed to associate with and internalize the bacteria for 30 minutes before flow cytometric analysis. The curves represent the percentage of cells that were associated with bacteria as a function of the MOP. The inset displays the MOP50 for each opsonization condition. B The MFI of THP1 cells in the FITC channel indicates the effect of each antibody on bacteria association to THP1 cells at MOP 400. C THP-1 cells were incubated as in (A) but only the percentage of cells with internalized bacteria were plotted for each MOP. D MFI of THP-1 cells which had internalized bacteria preopsonized with $10 \mu \mathrm{g} / \mathrm{ml}$ individual antibodies are presented at an MOP of 400 (internalized bacteria channel). E Heat killed SF370 opsonized with Ab25 or Xolair at a range of concentrations $(0.017-40 \mu \mathrm{g} / \mathrm{ml})$ were incubated with THP-1 cells at MOP 150. Phagocytosis was assessed as in (B). The data shown in this figure is from the pooled results of three independent experiments. Error bars represent the SEM. Statistical significance was assessed using one-way ANOVA with KruskalWallis multiple comparison correction and ${ }^{*}$ denotes $p<0.05$, ${ }^{* *}$ for $p<0.01$, ${ }^{* \star *}$ for $\mathrm{p}<0.001$ and $^{* * * \star}$ for $\mathrm{p}<0.0001$.

TX-MS first models quaternary conformations of protein complexes that are, in a second step, confirmed by targeted cross-linking analysis of the most high-scoring models. The high-resolution models of the Fab fragments of Ab25, Ab32, and Ab49 to their respective epitopes on M protein (Fig. 5) revealed a high degree of structural similarity between Ab25

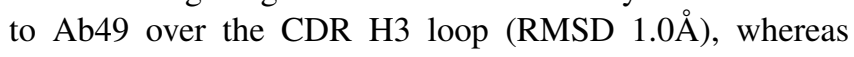
the conformation of Ab32 CDR H3 is more divergent (Fig. 5B-C). The conservation at the primary amino acid sequence level of Ab25 and Ab49 is less evident (Fig. 5A). The subsequent targeted cross-linking analysis resulted in the identification of ten cross-linked peptides between Ab25 and M1-protein. These cross-links are found between the $\mathrm{F}(\mathrm{ab})_{2}$ and two different regions on the M-protein, indicating that $\mathrm{Ab} 25$ has two different binding-sites in the B-S-C region (Fig. 5D and Fig. 5F, Supp. Table 1, Supp. Fig. 4A-J). Superimposing the cross-linked distant constraints onto high-resolution docking models, shows that $\mathrm{Ab} 25 \mathrm{~F}(\mathrm{ab})_{2}$ can simultaneously bind the two cross-linked 
Figure 4
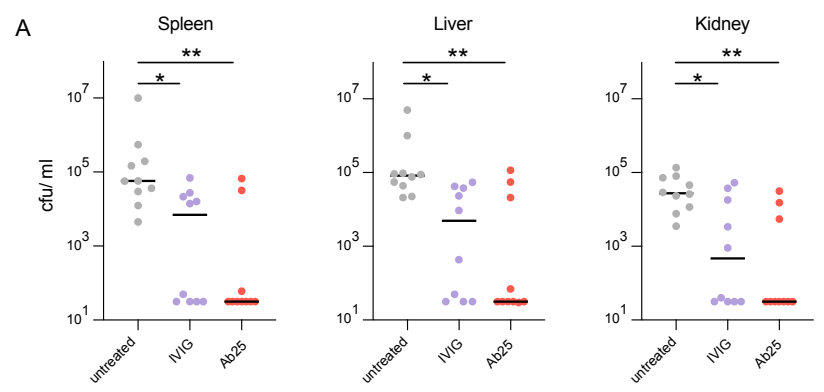

B
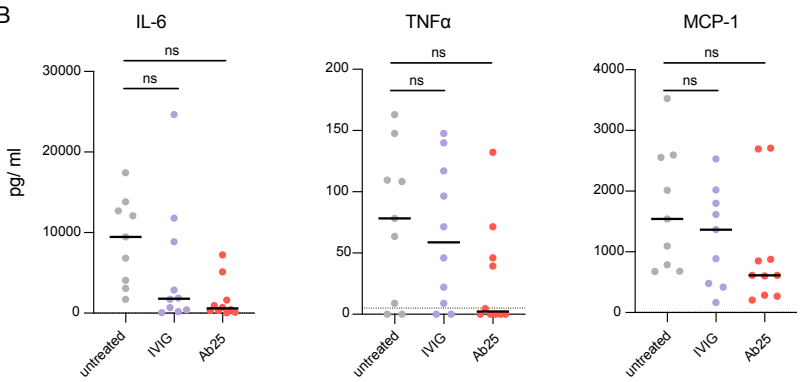

plasma from the original $\mathrm{B}$ cell donor and Ab25 significantly obstructed Fc-binding, whereas IVIG, Ab32 and Ab49 did not. Since Ab49 and Ab25 share one similar epitope, located above the $S$ region, it indicates that binding there alone is not sufficient to disrupt the $\mathrm{Fc}$ interaction, and strongly suggests that this is due to a dual-Fab cis binding capacity of Ab25.

Fig. 4. Anti-M antibody protects mice from GAS infection. C57/BL6 mice were pretreated with $10 \mathrm{mg}$ IVIG or $0.4 \mathrm{mg}$ Ab25 per mouse prior to subcutaneous infection with $10^{6} \mathrm{CFU}$ of GAS (S. pyogenes AP1). The animals were sacrificed after 24 hours. A The bacterial burden in spleen, kidney and liver tissue was measured by colony counts. B Cytokine levels in plasma was assessed using a cytometric bead array. The data is pooled from two independent experiments (5 mice per condition, per set). Statistical significance as assessed using one-way ANOVA with KruskalWallis multiple comparison correction and ${ }^{*}$ denotes $p<0.05,{ }^{* *}$ for $p<0.01,{ }^{* \star *}$ for $p<0.001$ and ${ }^{* * * *}$ for $p<0.0001$.

epitopes without inducing large conformational changes in the hinge region. This implies that Ab25 is capable of dual-Fab binding in an intramolecular cis-binding fashion to two distinct, non-identical epitopes. In contrast, the crosslink analysis of M-Ab49 generated two unique cross-linked peptides confined to only the upper epitope found with Ab25 (Fig. 5E, Supp. Table 1, Supp. Fig. 4K-L). Intriguingly, Ab25 binds across the M1 protein S-region (Fig. 5F) that has previously only been associated with $\mathrm{Fc}$-mediated binding (14, 21).

To further investigate the differences in the observed binding sites, we used site-localization microscopy (41), where the relative distance between fluorescently labeled cell wall and antibody binding epitopes is determined by repeated measures of individual bacteria (Fig. 5G). The height analysis showed that all monoclonal $\mathrm{F}(\mathrm{ab})_{2}$ fragments bind close to the Fc binding domain (S) on the M1 protein (compared to Xolair Fc binding), which supports the TX-MS results. Since the antibodies appear to interact with epitopes close to the Fc binding $\mathrm{S}$ domain (as seen in Fig. 5D-F), we further investigated if any of the antibodies could interfere with $\mathrm{Fc}$ binding. The dual-Fab cis binding of Ab25 covers the $\mathrm{S}$ domain (colored in orange in Fig. 5D, F) and would obstruct Fc binding, whereas single Fab interactions would have a smaller or no interference with Fc-binding. We measured the binding of fluorescent Xolair to SF370 bacteria that had been preincubated with antibody samples (Fig. 5H). Both blood Dual-Fab cis mode of interaction is required for
functional antibody binding. Dual-Fab cis antibody binding of two identical Fabs to two different epitopes on a single protein is, to our knowledge, a novel, previously not observed, mode of antibody interaction. Combined with the fact that dual-Fab cis binding is connected with a clear gain in immunological protective function prompted us to verify this finding and elucidate the particular nature of Ab25's dual-Fab binding capacity. First, we investigated the ability of single Ab25 Fabs to obstruct Fc binding. We used IgdE protease (42) to prepare intact single Fabs of Ab25. If binding of single Fabs to either Ab25 binding site on M protein could sustain a steric hindrance, we should see a reduction in $\mathrm{Fc}$ binding. However, $\mathrm{Fc}$ binding was not affected by single Ab25 Fabs (Fig. 6A), suggesting that obstruction of Xolair binding occurs via dual-Fab binding. Second, since Ab25 works well in ELISA (Fig. 2B), we wanted to see if we could inhibit Ab25 binding with M1-based fragments (Supp. Fig. 5B) that only harbors one of the binding sites. If Ab25 could bind to the single epitopes on their own, it should be possible to reduce binding with the fragments. However, M1-binding was not affected by the fragments (Fig. 6B), nor could we see binding to the fragments in a non-competitive ELISA assay (Supp. Fig. 5A). Third, we wanted to see how well different forms of the antibodies could bind to bacteria. We compared the binding of whole IgG, $\mathrm{F}(\mathrm{ab})_{2}$, and single Fabs to SF370. Strikingly, Ab25 single Fabs could not bind to the bacteria, whereas Ab49 Fabs increased their binding (Fig. 6C). The latter is the expected result since single Fabs should have easier access and, yet the results reveal that Ab25's predominant mode of interaction with $\mathrm{M}$ protein is dual-Fab cis binding. To assess how much weaker the binding via single Fabs is, we performed affinity measurements of single Fabs. These showed that Ab25 Fab binding has a 2000-fold lower affinity $\left(4.4 \mathrm{mM}^{-1}\right)$, compared to $\mathrm{F}\left(\mathrm{ab}^{\prime}\right)_{2}$ binding $\left(2.3 \mathrm{nM}^{-1}\right.$, Supp Fig. 5C). These results demonstrate that $A b 25$ requires a dual-Fab cis mode of interaction to bind effectively and exert a protective function.

\section{Discussion}

In this study, we describe a new broadly-binding monoclonal antibody which binds to the central region of the $\mathrm{M}$ protein and mediates bacterial clearance. Interestingly, this antibody has a peculiar mode of interaction with its target as it contacts the $\mathrm{M}$ protein via two distinct epitopes. We now understand that in addition to the classical antibody-antigen interactions which are extensively studied, that dual-Fab binding 
bioRxiv preprint doi: https://doi.org/10.1101/2021.03.01.433494; this version posted March 19, 2021. The copyright holder for this preprint (which was not certified by peer review) is the author/funder, who has granted bioRxiv a license to display the preprint in perpetuity. It is made available under aCC-BY-NC-ND 4.0 International license.

Figure 5

CDR H3 loop MSA

AB25 CARSYPHKRWL--RPPFD

AB49 CVRDSR----F--WGIFD

AB32 CAROGFDTR---GEDAFE

* * *

CDR L3 loop MSA

AB25 OYNSYPV--TFGOGTKV

AB49 QRSNWPP--TFGQGTKV

AB32 QRSGWPSIFTFGPGTKV

*..: $* * * * * * *$

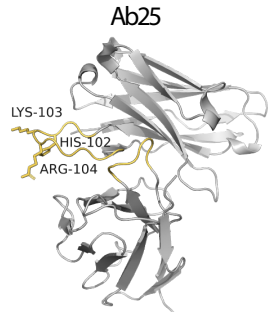

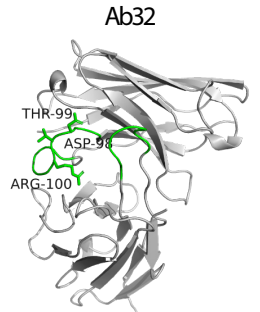

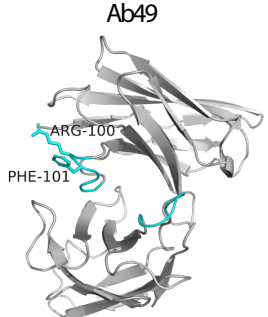

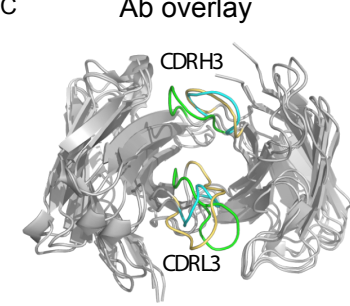

D

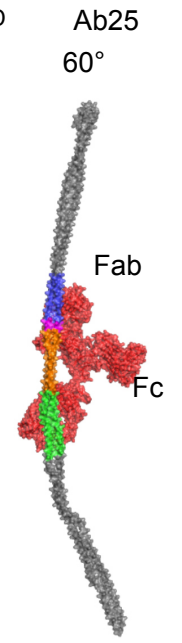

F M1 domains

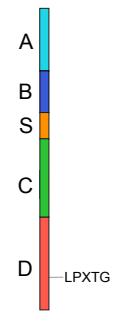

\section{$0^{\circ}$}

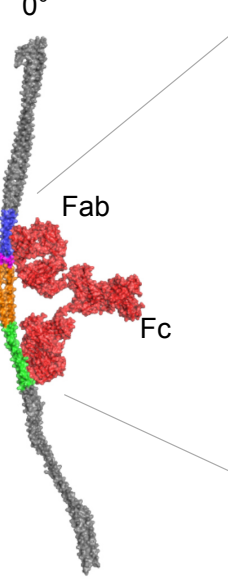

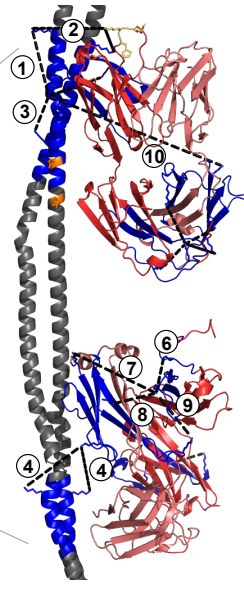

E

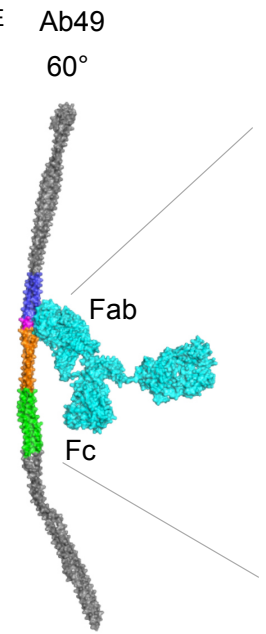

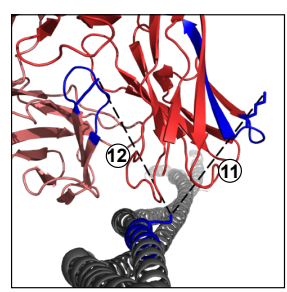

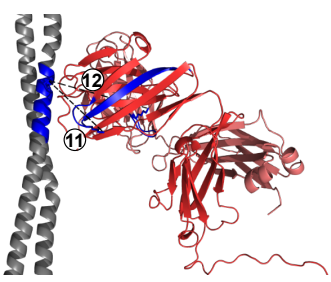

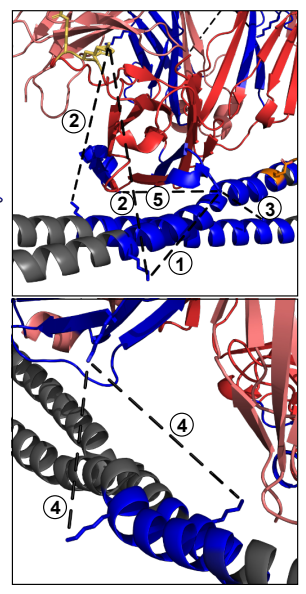

H Fc binding

G Antigen height

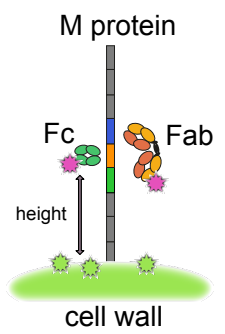

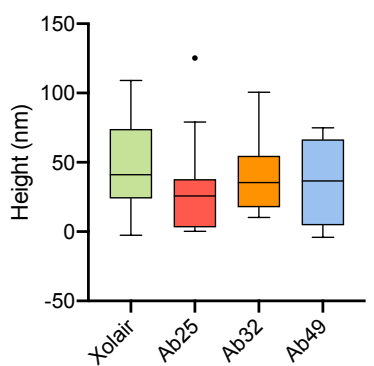
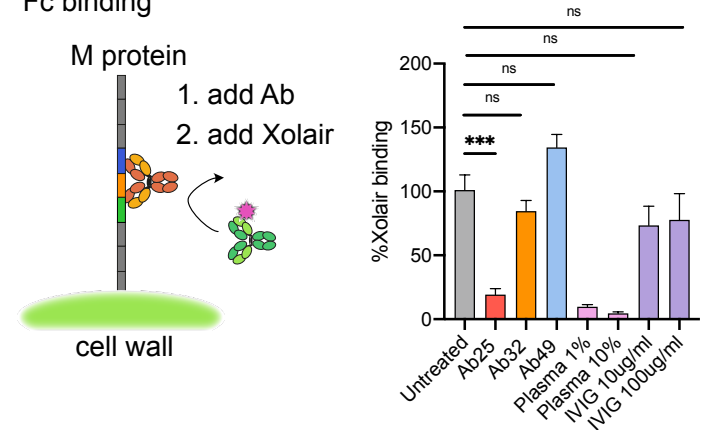

Fig. 5. Structural epitope characterization reveals dual-Fab cis binding mode of interaction. A Multiple sequence alignment reflects the $\mathrm{L} 3-\mathrm{H} 3 \mathrm{l}$ loop differences on the amino acid sequence level. B Representations of the Fab fragments of the modelled antibodies Ab25, Ab32 and Ab49. In each antibody, the CDR H3 and L3 loops are indicated (Ab25, yellow; Ab32, green; and Ab45, turquoise). C Structural alignment of Ab25 (yellow CDR loops), Ab32 (green loops) and Ab49 (turquoise loops). D The M1 interaction sites of $A b 25$ (red). A rotation of $60^{\circ}$ along the y-axis has been applied between the views. The length of contact surface is $45 \AA$ in the upper binding site (B2-B3-domain) and 18Å in the lower (C-domain). E The M1 interaction site of Ab49 (turquoise) is presented. The length of contact for Ab49 (B2-B3 domain) is approximately $16 \AA$. Insets in D and $E$ represent a full-length model generated by TX-MS 40, showing the Fab-mediated interaction of Ab25 or Ab49 (heavy chain in dark red, light chain in a lighter shade) with the M1 protein (in gray). Crosslinked peptides are indicated in dark blue, and crosslinks between lysine (K) residues as dashed black lines. The CDR $\mathrm{H} 3$ loop is shown in yellow (for Ab25) or in red (for Ab49). There are two interaction sites for Ab25 on the M1 protein, the upper one in the B2-B3-domain (inset) supported by 4 crosslinks and the lower one in the C1-domain (inset) by 6 crosslinks. Only one interaction site for Ab49 with M1 exists, and it is supported by 2 crosslinks. F Schematic representation the M1 protein and its domains. The protein is associated with the bacterial cell wall through the LPXTG motif in the C-terminal D domain. G The Fab epitopes as well as the Fc-binding region on the $\mathrm{M}$ protein are estimated by a fluorescence localization averaging method using structured illumination microscopy (SIM) images 41 . A relative binding site is determined by resolving the distance between the antibody and a reference channel (WGA, binds cell wall) using the cumulative signals from many images. The results shown here are from 4 independent experiments with $\mathrm{N}=9,13,9,9$, respectively. $\mathbf{H}$ Binding of Alexa647-conjugated Xolair (100 $\mu$ g/ml) to SF370 after pre-treatment with indicated antibody samples $(10 \mu \mathrm{g} / \mathrm{ml})$. The data is from 3 independent experiments pooled together. Statistical significance was assessed using one-way ANOVA with Kruskal-Wallis multiple comparison correction and ${ }^{*}$ denotes $p<0.05$, ${ }^{\star *}$ for $p<0.01$, ${ }^{\star * *}$ for $p<0.001$ and ${ }^{\star * * *}$ for $p<0.0001$. 

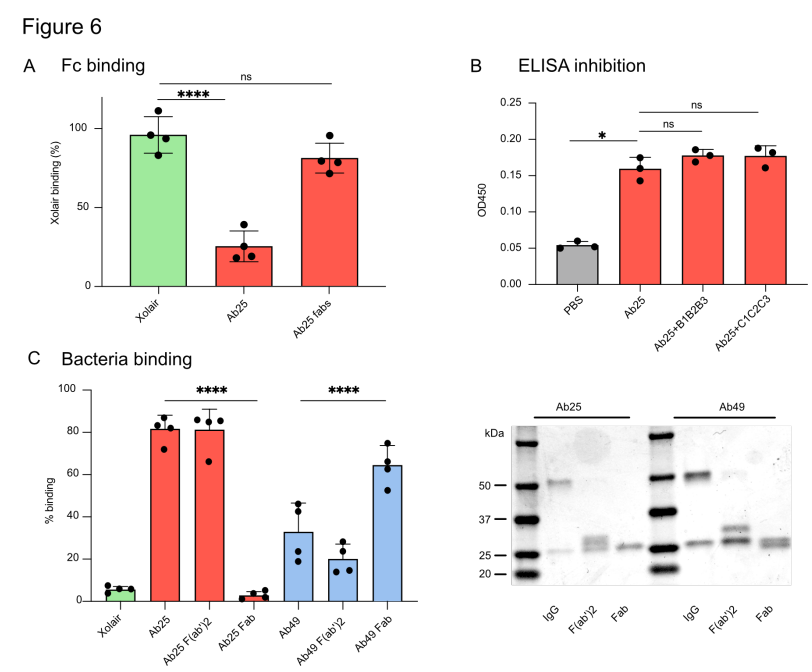

Fig. 6. Dual-Fab mode of interaction is required for functional antibody binding $\mathbf{A}$ Heat killed bacteria previously stained with Oregon Green were incubated with $10 \mu \mathrm{g} / \mathrm{ml}$ of Ab25 or lgdE-digested (Spoerry et al., 2016) Ab25 (Fabs). The bacteria were then incubated with fluorescently labelled Xolair (AF647) before being analyzed with flow cytometry. Bacteria which bound Xolair via its $\mathrm{Fc}_{\mathrm{c}}$ binding are shown as positive. B A competition anti-M protein ELISA was performed where free M1 fragments were mixed with $A b 25$ at equimolar ratios $(10 \mu \mathrm{g} / \mathrm{ml})$. The wells were then washed, and the signal developed using Protein G-HRP. C Binding properties of Xolair, IdeS-cleaved or IgdE-cleaved Ab25 or Ab49 were studied as previously by mixing the antibodies with heat killed, Oregon Green bacteria. The bacteria were then washed and stained with Alexafluor 647-conjugated Fab anti-Fabs and analyzed by flow cytometry. The panel to the right shows SDS-PAGE analysis of the antibodies used in the binding analysis. The data represents pooled results from four independent experiments. Statistical significance was assessed using one-way ANOVA with Kruskal-Wallis multiple comparison correction and * denotes $p<0.05$, ${ }^{\star *}$ for $p<0.01,{ }^{* * *}$ for $p<0.001$ and ${ }^{* * * *}$ for $p<0.0001$

of antibodies to antigens can enhance antibody function and might have therapeutic potential. Mass spectrometric analysis of anti-M antibodies crosslinked to $M$ protein, coupled with biochemical and immunological analysis, revealed that dual-Fab cis binding around the $\mathrm{M}$ protein $\mathrm{S}$ region can mediate phagocyte engagement and streptococcal phagocytosis. Dual-Fab cis binding, as seen with Ab25, seems to be a deterministic factor regarding the triggering of an immune response. In contrast, single-Fab binding, as seen with the closely located Ab49 has little or no immunological effect in the assays tested. It has been previously shown that antibodies against the hypervariable region or C-repeats (10, 16, 43, 44) of the M protein can also be opsonic and mediate phagocytosis. Therefore, while in the context of the $\mathrm{M}$ protein central region, dual-Fab binding antibodies are opsonic, other functional interactions between antibodies and antigens clearly exist. It is interesting to note that earlier studies on M6 protein revealed the central $\mathrm{M}$ region not only to be conserved amongst many $\mathrm{M}$ proteins but also non-opsonic (43), mirroring the results we observe with $\mathrm{Ab} 32$ and Ab49. The dual-Fab interaction of Ab25 seems to be the deciding factor make it opsonic, while still retaining the cross reactivity with $\mathrm{M}$ proteins due to the conserved nature of the central $\mathrm{M}$ region.

The fact that Ab25 and Ab49 bind to such a similar location, yet their binding leads to such different outcomes, provides an excellent internal control for dual-Fab cis binding, as well as prompts questions as to why it is so beneficial for immune stimulation. From a structural perspective, a two-point attachment is much more stable than a one-point attachment, probably stabilizing the $\mathrm{IgGFc}-\mathrm{Fc} \gamma$ receptor interaction. It would also provide a consistent angle of interaction, which might aid the clustering of receptors. The angle is relevant because the presentation of IgGFc's pointing in different directions could interfere with the zipper-like mechanism that $\mathrm{Fc} \gamma$ receptors typically use during phagocytosis (45). The specific orientation that $\mathrm{Ab} 25$ adapts when binding $\mathrm{M}$ protein results in the $\mathrm{IgGFc}$ being oriented perpendicular relative to $\mathrm{M}$ protein. This happens to be an optimal angle at which $\mathrm{Fc} \gamma$ receptors interact with IgGFc (46). Instead, interactions between IgA and Fc $\alpha$ receptors would have benefitted from an antibody being rotated $90^{\circ}$ from that of Ab25 (47). Recent findings indicate that both antigen height, whereby below $10 \mathrm{~nm}$ is beneficial (48), and pericellular barriers, whereby transmembrane pickets obstruct interaction (49), are important factors to consider for effective phagocytosis. Given that all three of our monoclonals bind at a similar height (40-50 $\mathrm{nm})$, this in and of itself cannot be an explanation here. However, it is possible that the stable dual-Fab interaction, in practice, shifts the perceived antigen height and thus results in a relatively closer bacteria-phagocyte interaction. In this case, the pericellular barrier would then also be reduced by the same distance, allowing a more productive phagocytic interaction. Another obvious mechanism could be the reduced IgGFc binding that $\mathrm{Ab} 25$ achieves by spanning the $\mathrm{IgGFc}$ binding site (S region). However, this is most likely not the case for two reasons. First, the IgGFc binding has a low affinity in the $\mathrm{mM}$ range and only becomes relevant at high IgG concentrations, magnitudes larger than those used in the phagocytosis experiments. Second, if the Fc binding could block phagocytosis, then the phagocytosis experiments with mixed monoclonals would see an additive effect, as Ab25 would block Fc binding, allowing the other antibodies to function. As we saw no additive effect whatsoever, this cannot be the case. The reduced IgGFc binding that Ab25 confers might have other protective effects to the host that remain to be investigated in future studies.

The requirement of dual-Fab cis binding to separate epitopes that Ab25 exhibits, is an unexpected mode of functional antibody interaction, adding to the already astounding diversity found in antibodies (50). A related phenomenon to the dualFab binding is the case of the anti-HIV 2G12 antibody (51) which has a mutation in its hinge region leading to Fab dimerization (52). The two fabs of 2G12 bind to high-mannose sugars but due to the fact of their unorthodox dimerization, essentially behave as one large Fab (53). Our Ab25 seems to have a classical antibody structure. In fact, normal single Fab-based interactions between multiple anti-HIV glycan antibodies gave similar biological outcomes as 2G12 (for a review see (54)). This indicates that while $2 \mathrm{G} 12$ has an unorthodox structure, its function is correlated to the specific epitope and not due to a distinct mode of interaction. In the 
context of unorthodox antibodies, bispecific antibodies (55) or antigen clasping antibodies (56) have been engineered for improved functionality, and here we show that evolution has resulted in similar outcomes. The results presented here reveal an, up till now, unknown added value of using $\mathrm{F}\left(\mathrm{ab} \mathbf{b}_{2}\right)_{2}$ fragments rather than Fabs when screening for functional antibodies.

Our results may partly explain why children and adolescents suffer the most from recurring GAS infections (57), and could be related to the observation that frequent infections are needed to generate long-term immunity (22). Antibody hypermutation after multiple rounds of GAS infection could be required to generate dual cis binding antibodies, allowing them to bypass the elaborate bacterial immune evasive mechanisms. It is difficult to predict how common this mode of binding is. Still, it is not unlikely that other bacterial proteins might be targeted by dual-Fab binding antibodies, as adhesins or other molecules with long repetitive structures are common amongst bacteria (58).

Dual-Fab cis binding antibodies could have broad implications for antibody function and vaccine design. Our findings could explain why attempts at generating an effective vaccine against GAS have so far been unsuccessful (24). Even if a vaccine can induce high titers, a large portion of these antibodies could be non-functional. If it turns out that dual-Fab cis binding antibodies are critical for function, antibody-based vaccine development strategies must be reconsidered. If vaccine peptides do not maintain conformational integrity (59) or span dual-Fab possible epitopes (10-15 nm separation), they might not be able to exhibit effective antibody-based immunity. Cell-mediated immunity would not be affected since T cell-MHC interaction, by definition, needs to be based on short peptides. The discovery and characterization of a protective antibody against experimental GAS infection, opens up the possibility for monoclonal immunotherapy. A particularly useful application would be as a complementary treatment in the management of an invasive GAS disease, one of the most critical and feared conditions in infection medicine.

\section{Methods}

Single B cell purification, baiting and isolation B cell isolation was performed as described previously (60), with some modifications. Briefly, $35 \mathrm{ml}$ of blood was drawn (into citrated collection tubes) from a young woman who had recently recovered from a group A streptococcal infection. Collection and analysis of human blood samples were approved by the regional ethics committee, permit number 2015/801. The blood was treated with $2.5 \mu \mathrm{l} / \mathrm{ml}$ Rosettesep B (Stemcell technologies) for 20 mins at room temperature. The blood was then diluted 1:1 in phosphate buffered saline (PBS) and layered onto Lymphoprep gradients. After centrifugation ( $30 \mathrm{mins}$ at $800 \mathrm{xg}$ ), the plasma was collected and frozen while the B cell layer (around $7 \mathrm{ml}$ ) was removed, diluted with $43 \mathrm{ml}$ of PBS, and centrifuged again. This washing step was repeated twice. The B cells were counted and kept at room temperature for staining (typical yields are 2-5 million cells per $30-40 \mathrm{ml}$ of blood).

B cell staining, baiting and sorting The B cells were concentrated into a final volume of $500 \mu \mathrm{l}$ in PBS. The cells were then blocked with 5\% BSA for 20 minutes before being stained with antibodies against CD19-PE (BD-555413), CD3-BV510 (BD-564713), and IgG-BV421 (BD-562581). The B cells were also labelled with the Sytox-FITC live/dead stain (Thermofischer-S34860). Baiting of the B cells was done using soluble M1 protein isolated from an MC25 group A streptococcus M1 strain. The M1 protein isolation procedure was previously described elsewhere (61). The M1 protein was directly conjugated to Alexa Fluor 647 using the microscale labeling kit (Invitrogen). In addition to the antibodies and live/dead stains, $0.1 \mu \mathrm{g} / \mathrm{ml}$ of AF694-M1 was added to the cells and the mixture was incubated at $32^{\circ} \mathrm{C}$ for 20 minutes (M1 undergoes a conformational change at $4^{\circ} \mathrm{C}$ which could obscure important epitopes $\left.(62)\right)$. After the incubation, the cells were washed with PBS twice and were kept on ice until further analysis. The gates for sorting were set on a FACSAriaFusion sorter using unstained cells and FMO-1 samples. A total of 100 cells were sorted from 2.5 million B cells directly into $10 \mu \mathrm{l}$ of water containing RNase inhibitor in 96-well plates and were immediately transferred to a $-80{ }^{\circ} \mathrm{C}$ freezer. The cells at this point would have been lysed due to osmotic pressure and the RNA stabilized in solution.

Reverse transcription, family identification and cloning The cells previously frozen in plates were thawed on ice and RT-PCR was performed using the OneStep RT-PCR kit (Qiagen) protocol without modification. The primer sequences used in the PCR steps were taken directly from the Smith et al (2009) paper without any modifications. After the RT-PCR, the nested PCR was performed and the bands corresponding to the variable regions of the heavy and light chains were sequenced to identify the antibody families. Family-specific cloning primers were used to clone the variable chains into the plasmids containing the constant regions of the heavy and light chains. The expression plasmids were generously donated by Dr. Patrick Wilson's group.

General cell culture and transfection THP-1 cells (Leukemic monocytes) were maintained in RPMI media supplemented with L-Glutamine and 10\% FBS. The cells were kept at a cell density between $5-10 \times 10^{5}$ cells per ml. THP-1-XBlue cells were maintained like regular THP-1 cells. HEK293 cells were maintained in DMEM supplemented with L-Glutamine and 10\% FBS. The cells were never allowed to grow to $100 \%$ confluency. The day before transfection, $8 \times 10^{6}$ cells were plated in circular $150 \mathrm{~mm}$ dishes. This transfection format allowed for the most efficient antibody recovery.

Transfection, expression and purification In total, 10 
antibody construct pairs were successfully generated from 100 starting cells. The Antibody pairs were transformed into Mix'n'go E. coli. Transformant colonies were verified by sequencing and the plasmids were further propagated and DNA was extracted using a Zymoresearch midiprep kit. Plasmid pairs encoding full mature antibodies were co-transfected into HEK293 cells using the PEI transfection method (https://www.addgene.org/protocols/transfection/). Cells were briefly treated with $25 \mu \mathrm{M}$ Chloroquine for 5 hours. Thereafter, $20 \mu \mathrm{g}$ of heavy and light chain expression plasmid DNA were diluted in OptiMEM (Life technologies) media containing polyetheleneimine (PEI) at a 1:3 ratio (for $50 \mu \mathrm{g}$ of DNA, $114 \mu \mathrm{l}$ of a $1 \mathrm{mg} / \mathrm{ml}$ PEI stock was used). The cells were incubated at $37^{\circ} \mathrm{C}$ for 18 hours before they were washed 2 times with PBS and the DMEM media was exchanged with OptiMEM. The cells were incubated for a further 72 hours before the supernatants were collected. The antibodies in the supernatants were purified using Protein G beads in a column setup. The antibodies were then titrated by comparing their concentrations on an SDS-PAGE to serial dilutions of a known concentration of Xolair (commercially bought Omalizumab, stored at $150 \mathrm{mg} / \mathrm{ml}$ ).

Bacterial strains, growth, and transformation Streptococcus pyogenes strain SF370 (emm1 serotype) and AP1 (emm1 serotype) was grown in Todd-Hewitt Yeast media (THY) at $37^{\circ} \mathrm{C}$. The bacteria were maintained on agar plates for 3 weeks before being discarded. We chose to use SF370 in all of our experiments since it is an M1 serotype strain lacking protein $\mathrm{H}$ which is a complicating factor (due to its strong Fc binding capacity and extensive homology with $\mathrm{M}$ protein (63)). The different $M$ serotypes which were used in our cross-strain comparison were clinical isolates, previously deposited into our in-house biobank. For experiments, overnight cultures were prepared in THY and were diluted 1:20 on the day of the experiments. After dilution, three hours of growth at $37^{\circ} \mathrm{C}$ ensured that the bacteria were in mid-log growth. For the generation of GFP-expressing strains, the SF370 and its $\Delta \mathrm{M}$ isogenic counterpart were grown to mid-log before being washed with ice-cold water. The electrocompetent bacteria were electroporated with $20 \mu \mathrm{g}$ of the pGFP1 plasmid and plated on Erythromycin supplemented THY plates. The successful transformants were fluorescent when examined under ultraviolet light. Heat killing the bacteria was done by growing the cultures to mid $\log$, washing them once in PBS and incubating them on ice for 5 minutes. The bacteria were then heat shocked at $80^{\circ} \mathrm{C}$ for 5 minutes before being placed on ice for 15 minutes. For the phagocytosis assay, the heat killed bacteria were centrifuged at $8000 \mathrm{x}$ g for 3 minutes and resuspended in Na-medium $(5.6 \mathrm{mM}$ glucose, $127 \mathrm{mM} \mathrm{NaCl}, 10.8 \mathrm{mM}$ $\mathrm{KCl}, 2.4 \mathrm{mM} \mathrm{KH} \mathrm{PO}_{4}, 1.6 \mathrm{mM} \mathrm{MgSO}$, $10 \mathrm{mM}$ HEPES, $1.8 \mathrm{mM} \mathrm{CaCl}_{2} ; \mathrm{pH}$ adjusted to 7.3 with $\mathrm{NaOH}$ ). Heat-killed bacteria were stained with $5 \mu \mathrm{M}$ Oregon Green $488-\mathrm{X}$ succinimidyl ester (Thermofischer) at $37^{\circ} \mathrm{C}$ under gentle rotation and protected from light for $30 \mathrm{~min}$. The bacteria were then centrifuged and resuspended in Sodium carbonate buffer $(0.1 \mathrm{M}, \mathrm{pH} 9.0)$ for an additional staining step with the $\mathrm{pH}$-sensitive dye CypHer5E (Fischer scientific). This was used at a concentration of $7 \mu \mathrm{g} / \mathrm{ml}$ in a volume of $1.5 \mathrm{ml}$ for $2 \mathrm{~h}$ at room temperature under gentle rotation, protected from light. The samples were washed once with Na-medium to remove excess dye and stored at $4^{\circ} \mathrm{C}$ for later use.

Antibody screening and flow cytometry For ELISAs: ELISA plates were coated overnight with $10 \mu \mathrm{g} / \mathrm{ml} \mathrm{M} 1$ at $4^{\circ} \mathrm{C}$, which had been purified from MC25 culture supernatants (61). After a 1-hour incubation at $37^{\circ} \mathrm{C}$, the wells were washed 3 times with PBST and blocked with 2\% BSA in $300 \mu \mathrm{l}$ PBST for 30 minutes. After blocking, $300 \mu \mathrm{l}$ of antibody containing supernatants were added to the wells, or diluted donor plasma as a control. The samples were incubated for 1 hour at $37^{\circ} \mathrm{C}$, washed, and a solution of Protein G-HRP (diluted 1:3000) was added to the wells and incubated at $37^{\circ} \mathrm{C}$ for 1 hour. The samples were then washed and developed with $100 \mu \mathrm{l}$ developing reagent (20 ml Substrate buffer NaCitrate $\mathrm{pH} 4.5+1 \mathrm{ml}$ ABTS Peroxide substrate $+0.4 \mathrm{ml} \mathrm{H} 2 \mathrm{O} 2$ ). Absorbance was read at OD450 following 5-30 minutes of color development at room temperature.

For ELISA using the shorter M1 B1B2B3 and $\mathrm{C} 1 \mathrm{C} 2 \mathrm{C} 3$ constructs, open reading frames encoding for the B1B2B3 repeats of the M1 protein (UniProt ID: Q99XV0, emm1; amino acids 132-194) and the $\mathrm{C} 1 \mathrm{C} 2 \mathrm{C} 3$ repeats (amino acids 229-348) were cloned at the Lund Protein Production Platform (LP3) (Lund, Sweden). The encoding sequences were ordered as a synthetic construct from Genscript (NJ, USA), and cloned into a pNIC28-Bsa4-based vector incorporating a tandem affinity purification tag (histidine-hemagglutininStrepII-tobacco etch virus protease recognition site) at the C-terminus of the construct. The constructs were expressed in Luria-Bertani Broth (Difco) supplemented with $50 \mathrm{~g} / \mathrm{ml}$ of kanamycin at $25{ }^{\circ} \mathrm{C}$ in E. coli TUNER (DE3) cells. For protein expression the temperature was lowered to $18{ }^{\circ} \mathrm{C}$ and the expression induced with $0.1 \mathrm{mM}$ IPTG at OD600 0.6. Expressed cells were harvested and resuspended in phosphate buffer $(50 \mathrm{mM} \mathrm{NaPO} 4,300 \mathrm{mM} \mathrm{NaCl}, 20 \mathrm{mM}$ imidazole, $\mathrm{pH}$ 8.0) supplemented with EDTA-free Complete Protease Inhibitor tablets (Roche). The cells were lysed using a French pressure cell at 18,000 psi. The lysate was cleared via ultracentrifugation (Ti 50.2 rotor, $244,000 \times \mathrm{g}, 60$ min, $4{ }^{\circ} \mathrm{C}$ ) and subsequently passed through a $0.45 \mu \mathrm{m}$ filter prior to loading on a HisTrap HP column (GE Healthcare). The column was washed with 20 column volumes (CVs) of phosphate buffer, and bound protein was eluted using a gradient of $0-500 \mathrm{mM}$ imidazole in phosphate buffer. Fractions containing the desired protein were pooled, and dialyzed against $1 \times$ phosphate buffer saline (PBS; $10 \mathrm{mM}$

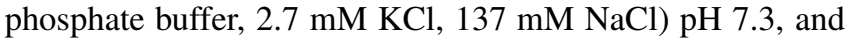
stored at $80^{\circ} \mathrm{C}$. These constructs were subsequently used to coat the ELISA wells or as competition for the $\mathrm{M}$ antibodies.

For flow cytometric screening: Overnights of SF370-GFP 
bacteria or its $\Delta \mathrm{M}$ counterpart were diluted 1:20 into THY and grown until mid-log. $100 \mu \mathrm{l}$ of the bacteria were distributed into wells of a 96 well plate. Antibodies purified from cell culture supernatants were diluted to $5 \mu \mathrm{g} / \mathrm{ml}$ and were digested with $1 \mu \mathrm{g} / \mathrm{ml}$ of IdeS for 3 hours at $37{ }^{\circ} \mathrm{C}$. The digested antibodies were further diluted 1:10 into the bacterial suspension. Reaching a final concentration of 0.5 $\mu \mathrm{g} / \mathrm{ml}$. The bacteria were incubated for 30 minutes at $37{ }^{\circ} \mathrm{C}$ before being washed twice with PBS. AF647-conjugated Fab $\alpha$-Fab antibody fragments were used as secondary antibodies to detect binding of the primary $\alpha-\mathrm{M}$ antibodies. After a 30-minute incubation with the Fab $\alpha$-Fab fragments, the bacteria were washed and analyzed on a Cytoflex flow cytometer (Beckman Coulter). The gates for the GFP-expressing bacteria were set using the SF370 parent strain (not expressing the GFP plasmid). GFP-expressing bacteria within the GFP-expressing gate were assessed for antibody staining (APC channel). Antibody staining reflects the presence of surface-bound primary-secondary antibody complexes and is indicative of bound anti-M antibodies.

For western blotting: Antibody reactivity to linear epitopes was assessed by probing the lysates of SF370 and its $\Delta \mathrm{M}$ mutant using western blotting. Briefly, pellets of logarithmically grown bacteria were incubated with phospholipase $\mathrm{C}$ for 30 minutes in PBS until the lysates became clear. The lysates were sonicated and cleared by centrifugation $(15,000$ $\mathrm{x} g$ for 3 minutes). We loaded $40 \mu \mathrm{g}$ of 5 replicate sets of SF370 vs $\Delta \mathrm{M}$ mutant protein on a gradient SDS-PAGE gel (4-20\%). The gel electrophoresis was run for 60 minutes to achieve protein separation. The proteins were transferred from the gel to a PVDF membrane which was blocked for 45 minutes with 5\% skimmed milk in PBST. The replicate lanes of the membrane were then cut and probed with 2 or $10 \mu \mathrm{g} / \mathrm{ml}$ of Xolair, Ab25, 32, 49 or IVIgG overnight at 4 ${ }^{\circ} \mathrm{C}$. The membranes were washed 3 times with PBST and probed with the secondary HRP-conjugated goat anti-human IgG secondary (Rockland) antibody for 1 hour at room temperature. The secondary was later washed, and the membrane developed using a chemilumunescence reagent (WestFemto substrate, Thermofischer).

Agglutination assays For agglutination assays: Overnight cultures of SF370 and its $\Delta \mathrm{M}$ strain were diluted $1: 5$ in RPMI and were treated with $100 \mu \mathrm{g} / \mathrm{ml}$ of the anti-M antibodies, or with 5\% donor plasma. It is crucial for this series of experiments that the bacteria are incubated in a cuvette and are not shaken or vortexed during incubation. At indicated time points, the OD600 of the bacteria was measured and at the 3.5 hour mark the cuvettes were photographed. For aggregate dissolution experiments: SF370 bacteria were grown overnight, diluted 1:20 in THY and left to grow for two hours. The bacteria were then supplemented with $100 \mu \mathrm{g} / \mathrm{ml}$ of the appropriate antibody. Two hours after inoculation, the bacteria were vortexed, imaged (randomly) and the aggregate areas were analyzed using Image $\mathbf{J}$.
SIM imaging Logarithmic phase bacteria were sonicated (VialTweeter; Hielscher) for 0.5 minutes to separate any aggregates and incubated fixed in $4 \%$ paraformaldehyde for 5 minutes on ice. The bacteria were thereafter washed with PBS twice (10,000 $\mathrm{x} g$ for $3 \mathrm{~min})$. SF370 was stained with Alexa Fluor 647-conjugated wheat germ agglutinin (WGA). Bacteria were incubated with IdeS-cleaved Xolair, Ab25, $\mathrm{Ab} 32$, and $\mathrm{Ab} 49$ and stained with fluorescently labelled IgGFab or IgGFc specific $\mathrm{F}\left(\mathrm{ab}^{\prime}\right)_{2}$ fragments (DyLight488conjugated anti-human IgGFc or IgGFab; Jackson ImmunoResearch Laboratory). Samples were mounted on glass slides using Prolong Gold Antifade Mountant with No. 1.5 coverslips. Images of single bacteria were acquired using an N-SIM microscope with LU-NV laser unit, CFI SR HP Apochromat TIRF 100X Oil objective (N.A. 1.49) and an additional $1.5 \mathrm{x}$ magnification. The camera used was ORCA-Flash 4.0 sCMOS camera (Hamamatsu Photonics K.K.) and the images were reconstructed with Nikon's SIM software on NIS-Elements Ar (NIS-A 6D and N-SIM Analysis). Images of the bacteria were acquired with 488 and $640 \mathrm{~nm}$ lasers. For site localization, single bacteria were manually identified and imaged in time series with 50 frames. The analysis pipeline for site localization was implemented in Julia and is available on GitHub (41). A cut off of initial signal-to-noise ratio (SNR) was set to 0.3 and timeframes included were the ones with at least $70 \%$ of the initial SNR.

Binding curves SF370 bacteria were grown to mid log, washed and $10 \mathrm{ml}$ of culture were concentrated into 1000 $\mu \mathrm{l}$ of PBS. The bacteria were stained with halving serial dilutions of the anti-M antibodies. $30 \mu \mathrm{l}$ of bacteria were used per every $100 \mu \mathrm{l}$ of IdeS treated antibody. The staining was performed at $4{ }^{\circ} \mathrm{C}$ for 30 minutes (with shaking) before the bacteria were washed and stained with an excess of AF647-conjugated Fab anti-Fab fragments in a volume of $30 \mu \mathrm{l}$ for 30 minutes at $4^{\circ} \mathrm{C}$ with shaking. The bacteria were then diluted to $250 \mu \mathrm{l}$ in PBS and analyzed by flow cytometry. Theoretical fit was done in MATLAB using fminsearch for an ideal binding curve with the dissociation constant as an unknown variable, as described (64).

Crosslinking of antibody $F\left(a^{\prime}\right)_{2}$-fragments to the M1protein For the crosslinking of Ab25, Ab32 and Ab49 $\mathrm{F}\left(\mathrm{ab}{ }^{\prime}\right)_{2}$ fragments to the M1 protein, we used two different preparations of the M1 protein; one expressed and purified as recombinant in E. coli as described for the B1B2B3 and $\mathrm{C} 1 \mathrm{C} 2 \mathrm{C} 3$ constructs above, and one purified from the culture supernatant of the S. pyogenes MC25 strain (61). The antibody $\mathrm{F}\left(\mathrm{ab}^{\prime}\right)_{2}$ fragments were cleaved and purified from the expressed intact antibodies using the FragIT-kit with Fc-capture columns (Genovis) according to the manufacturer's instructions. For crosslinking, $25 \mu \mathrm{g}$ of the recombinant M1 protein or $8 \mu \mathrm{g}$ of the MC25 M1 protein were incubated with $5 \mu \mathrm{g}$ of the respective $\left.\mathrm{F}(\mathrm{ab})_{2}\right)_{2}$ fragments in $1 \times \mathrm{PBS}$ pH 7.4 at $37{ }^{\circ} \mathrm{C}, 800 \mathrm{rpm}, 30 \mathrm{~min}$. Heavy/light disuccinimidylsuberate (DSS; DSS-H12/D12, 
Creative Molecules Inc.) resuspended in dimethylformamide (DMF) was added to final concentrations 250 and $500 \mu \mathrm{M}$ and incubated for a further of $60 \mathrm{~min}$ at $37^{\circ} \mathrm{C}, 800 \mathrm{rpm}$. The crosslinking reaction was quenched with a final concentration of $50 \mathrm{mM}$ ammonium bicarbonate at $37^{\circ} \mathrm{C}, 800 \mathrm{rpm}, 15 \mathrm{~min}$.

Sample preparation for MS The crosslinked samples mixed with $8 \mathrm{M}$ urea and $100 \mathrm{mM}$ ammonium bicarbonate, and the cysteine bonds were reduced with $5 \mathrm{mM}$ TCEP $\left(37{ }^{\circ} \mathrm{C}\right.$ for $2 \mathrm{~h}, 800 \mathrm{rpm}$ ) and alkylated with $10 \mathrm{mM}$ iodoacetamide $\left(22{ }^{\circ} \mathrm{C}\right.$ for $30 \mathrm{~min}$, in the dark). The proteins were first digested with $1 \mu \mathrm{g}$ of sequencing grade lysyl endopeptidase (Wako Chemicals) $\left(37^{\circ} \mathrm{C}, 800 \mathrm{rpm}, 2 \mathrm{~h}\right)$. The samples were diluted with $100 \mathrm{mM}$ ammonium bicarbonate to a final urea concentration of $1.5 \mathrm{M}$, and $1 \mu \mathrm{g}$ sequencing grade trypsin (Promega) was added for further protein digestion $\left(37^{\circ} \mathrm{C}\right.$, $800 \mathrm{rpm}, 18 \mathrm{~h}$ ). Samples were acidified (to a final pH 3.0) with $10 \%$ formic acid, and the peptides purified with $\mathrm{C} 18$ reverse phase spin columns according to the manufacturer's instructions (Macrospin columns, Harvard Apparatus). Peptides were dried in a speedvac and reconstituted in $2 \%$ acetonitrile, $0.2 \%$ formic acid prior to mass spectrometric analyses.

\section{Liquid chromatography tandem mass spectrometry} (LC-MS/MS) All peptide analyses were performed on Q Exactive HF-X mass spectrometer (Thermo Scientific) connected to an EASY-nLC 1200 ultra-high-performance liquid chromatography system (Thermo Scientific). Peptides were loaded onto an Acclaim PepMap $100(75 \mu \mathrm{m}$ x 2 cm) C18 (3 $\mu \mathrm{m}, 100 \AA$ ) pre-column and separated on an EASY-Spray column (Thermo Scientific; ID $75 \mu \mathrm{m}$ x $50 \mathrm{~cm}$, column temperature $45^{\circ} \mathrm{C}$ ) operated at a constant pressure of 800 bar. A linear gradient from 4 to $45 \%$ of $80 \%$ acetonitrile in aqueous $0.1 \%$ formic acid was run for $65 \mathrm{~min}$ at a flow rate of $350 \mathrm{nl} \mathrm{min-1.} \mathrm{One} \mathrm{full} \mathrm{MS} \mathrm{scan} \mathrm{(resolution} 60000 @ 200$ $\mathrm{m} / \mathrm{z}$; mass range $390-1210 \mathrm{~m} / \mathrm{z}$ ) was followed by MS/MS scans (resolution $15000 @ 200 \mathrm{~m} / \mathrm{z}$ ) of the 15 most abundant ion signals. The precursor ions were isolated with $2 \mathrm{~m} / \mathrm{z}$ isolation width and fragmented using HCD at a normalized collision energy of 30. Charge state screening was enabled, and precursors with an unknown charge state and a charge state of 1 were rejected. The dynamic exclusion window was set to $10 \mathrm{~s}$. The automatic gain control was set to $3 \mathrm{e} 6$ and 1e5 for MS and MS/MS with ion accumulation times of $110 \mathrm{~ms}$ and $60 \mathrm{~ms}$, respectively. The intensity threshold for precursor ion selection was set to $1.7 \mathrm{e} 4$.

Computational modeling Several protocols of Rosetta software suit (65) were employed for macromolecular modeling of this study. To model the full-length antibodies, first the antigen-binding domains were characterized using Rosetta antibody protocol (66). Then, comparative models have been generated for both heavy and light chains using RosettaCM protocol (67) and aligned on the antigen-binding domains to represent the initial structure of the antibody. HSYMDOCK (68), and DaReUS_loop (69) web servers were used for symmetric docking of the Fc-domains and to model the hinge regions, respectively. Finally, 4K models were produced for each antibody as the final refinement and the top-scored models were selected based on XLs derived from mass spectrometry combined with rosetta energy scores. Moreover, to characterize the M1 antibody interactions, TX-MS protocol were used (40), through which $2 \mathrm{~K}$ docking models were generated and filtered out using distance constraints from DDA data. A final round of high-resolution modeling was performed on top models to repack the sidechains using RosettaDock protocol (70).

Fluorescent Xolair competition experiments Logarithmically grown SF370 bacteria were heat killed and labelled with Oregon Green (as described previously). The bacteria were mixed with antibodies or plasma/IVIG and incubated for 30 minutes at $37^{\circ} \mathrm{C}$ while shaking. Fluorescently conjugated Xolair (conjugated to Alexafluor 647 using the protein labeling kit (Invitrogen) according to the manufacturer's instructions) was then added to the bacteria at a concentration of $100 \mu \mathrm{g} / \mathrm{ml}$ for an additional 30 minutes before being directly analyzed by flow cytometry. For experiments in which Fabs were used, the Fabs were generated using the Fabalactica digestion kit (Genovis) according to manufacturer's instructions.

Phagocytosis assay The phagocytosis experiments were performed using persistent association normalization (38). Prior to opsonization, the CypHer5E- and Oregon Greenstained SF370 bacteria were sonicated for up to $5 \mathrm{~min}$ (VialTweeter; Hielscher) to disperse any large aggregates of bacteria. Sonication was deemed sufficient when clump dispersal was confirmed by microscopy. Staining as well as bacterial count (events/ $\mu$ in the FITC + ve gate) was assessed by flow cytometry (CytoFLEX, Beckman-Coulter). The $\mathrm{pH}$ responsiveness of CypHer5E was tested by measuring the bacterial fluorescent staining in the APC channel before and after the addition of $1 \mu \mathrm{l}$ of sodium acetate ( $3 \mathrm{M}, \mathrm{pH} 5.0)$ to $100 \mu \mathrm{l}$ of bacterial suspension. The presence of an acid induced shift in fluorescence indicated successful staining. On the day of experiments, the appropriate number of bacteria were opsonized to suit each experiment. The opsonization with our M-specific antibodies, Xolair or with IVIG was performed at $37^{\circ} \mathrm{C}$ for 30 minutes. For experiments with a variable MOP, serial dilutions of the opsonized bacteria were made and used to incubate with the THP-1 cells. By gating on the leukocyte population (Supp. Fig. 3a), specifically on single cells (Sup. Fig 3b), we were able to group the cells into those associated with bacteria (FITC positive) and with internalized bacteria (FITC and APC positive) (Supp. Fig 3c-e). Panels shown in Supp. Fig 3c show non-interacting cells whereas Supplementary Figure $3 \mathrm{~d}$ and $3 \mathrm{e}$ show the result of phagocytosis at $37^{\circ} \mathrm{C}$ and $4^{\circ} \mathrm{C}$, respectively. In experiments where antibody concentration was the variable, serial dilutions of the antibodies were made in Na-medium in 96 well plates and the bacteria were directly added to the antibodies for opsonization. THP1 cells were washed 
in PBS on the day of the experiment and resuspended in Na-medium. The concentration of THP-1 cells was measured prior to phagocytosis by flow cytometry and adjusted to 2000 cells $/ \mu \mathrm{l}(100000$ cells per well). The cells were then added to the 96-well plates previously prepared with varying concentrations of previously opsonized bacteria (MOP) or with different antibody concentrations. Finally, $50 \mu \mathrm{l}$ of THP-1 cells were added on ice resulting in a final phagocytic volume of $150 \mu \mathrm{l}$. After a 5-minute incubation on ice, the plate was directly transferred to a shaking heating block set to $37^{\circ} \mathrm{C}$ while being protected from light or kept on ice as a control for internalization. Phagocytosis was stopped by putting the samples on ice for at least $15 \mathrm{~min}$ before data acquisition. Three experiments were performed to assess the association curves and four experiments were performed at MOP 400 to compare different antibodies. Flow cytometric acquisition was performed using a CytoFLEX (Beckman-Coulter) with $488 \mathrm{~nm}$ and $638 \mathrm{~nm}$ lasers and filters 525/40 FITC and 660/10 APC. Threshold was set at FSC-H 70,000 for phagocytosis and for bacteria FSC-H 2000 and SSC-H 2000. Gain was set to 3 for FITC and 265 for APC. Acquisition was set to capture at least 5000 events of the target population with a velocity of $30 \mu \mathrm{l} / \mathrm{min}$ taking approximately $30 \mathrm{~min}$ to assess all samples. Throughout the data acquisition the 96-well plate was kept on an ice-cold insert to inhibit further phagocytosis.

NFkB activity luciferase assay THP-XBlue-CD14 (Invivogen) cells were seeded at a density of 200,000 cells per well in 96 well plates. The cells were treated with the appropriate antibodies (at $0.5 \mu \mathrm{g} / \mathrm{ml}$ ) with or without M1 protein $(2 \mu \mathrm{g} / \mathrm{ml})$ for 18 hours at $37^{\circ} \mathrm{C}$. After the incubation, $20 \mu \mathrm{l}$ of the cell supernatant were aspirated and mixed with the developing reagent, as described by the assay instructions (QuantiBlue solution, Invivogen). The samples were incubated at $37{ }^{\circ} \mathrm{C}$ until development was appropriate and the OD650 measurement of the samples was done using a multi-well spectrophotometer.

Animal model All animal use and procedures were approved by the local Malmö/Lund Institutional Animal Care and Use Committee, ethical permit number 03681-2019. Nine-week-old female C57BL/6J mice (Scanbur/ Charles River Laboratories) were used. Monoclonal antibody Ab25 (0.4 mg/mouse), or intravenous immunoglobulin (10 $\mathrm{mg} /$ mouse) was administered intraperitoneally $6 \mathrm{~h}$ pre-infection. S. pyogenes AP1 was grown to logarithmic phase in Todd-Hewitt broth $\left(37^{\circ} \mathrm{C}, 5 \% \mathrm{CO} 2\right)$. Bacteria were washed and resuspended in sterile PBS. $10^{6} \mathrm{CFU}$ of bacteria were injected subcutaneously into the scruff leading to systemic infection within $24 \mathrm{~h}$. Mice were sacrificed 24 $\mathrm{h}$ post infection, and organs (blood, livers, spleens, and kidneys) were harvested to determine the degree of bacterial dissemination. The blood cell counts were analyzed by flow cytometry. Cytokines were quantified using a cytometric bead assay (CBA mouse inflammation kit, BD) according to manufacturer instructions.
Author contributions Conceptualization: WB, LB, OS, LM, JM and PN. Experimentation and data analysis: WB, LH, HK, VKA, TdN, SW, EB, DT, and TH. Writing original draft: WB and PN. All authors contributed to reading and editing the final manuscript.

Acknowledgements WB, LH, OS, LB, LM, JM and PN is funded by the Knut and Alice Wallenberg Foundation. TH and equipment were funded by IngaBritt och Arne Lundbergs Forskningsstiftelse. HK is funded by Swiss National Science Foundation (grant no. P2ZHP3_191289). The production of the recombinant $\mathrm{M} 1$ and the $\mathrm{B} 1 \mathrm{~B} 2 \mathrm{~B} 3$ and $\mathrm{C} 1 \mathrm{C} 2 \mathrm{C} 3$ constructs was performed at the Lund Protein Production Platform, Lund University, Sweden (http://www.lu.se/lp3). We thank Åsa Petersson for help with flow sorting and Gisela Hovold for technical assistance.

Conflicts of interest WB, LH, HK, OS, LB, LM, JM and PN have a patent application pending (P023265EP1) based on the findings in this manuscript.

\section{References}

1. V Pascual, Y J Liu, A Magalski, O de Bouteiller, J Banchereau, and J D Capra. Analysis of somatic mutation in five $\mathrm{b}$ cell subsets of human tonsil. The Journal of Experimental Medicine, 180(1):329-339, jul 1994.

2. P C Wilson, O de Bouteiller, Y J Liu, K Potter, J Banchereau, J D Capra, and V Pascual. Somatic hypermutation introduces insertions and deletions into immunoglobulin $v$ genes. The Journal of Experimental Medicine, 187(1):59-70, jan 1998.

3. Tomohiro Kurosaki, Kohei Kometani, and Wataru Ise. Memory b cells. Nature Reviews. Immunology, 15(3):149-159, mar 2015.

4. Joshua S Klein and Pamela J Bjorkman. Few and far between: how HIV may be evading antibody avidity. PLoS Pathogens, 6(5):e1000908, may 2010.

5. Jenny M Woof and Dennis R Burton. Human antibody-fc receptor interactions illuminated by crystal structures. Nature Reviews. Immunology, 4(2):89-99, feb 2004

6. Lenette L Lu, Todd J Suscovich, Sarah M Fortune, and Galit Alter. Beyond binding: antibody effector functions in infectious diseases. Nature Reviews. Immunology, 18(1):46-61, 2018.

7. Jonathan R Carapetis, Andrew C Steer, E Kim Mulholland, and Martin Weber. The global burden of group a streptococcal diseases. The Lancet Infectious Diseases, 5(11):685-694, nov 2005.

8. Timothy J Mitchell. The pathogenesis of streptococcal infections: from tooth decay to meningitis. Nature Reviews. Microbiology, 1(3):219-230, dec 2003.

9. Cheryl Y M Okumura and Victor Nizet. Subterfuge and sabotage: evasion of host innate defenses by invasive gram-positive bacterial pathogens. Annual Review of Microbiology, 68:439-458, jun 2014.

10. Fredric Carlsson, Karin Bergg, Margaretha St-Carlemalm, and Gunnar Lindahl. Evasion of phagocytosis through cooperation between two ligand-binding regions in streptococcus pyogenes m protein. The Journal of Experimental Medicine, 198(7):1057-1068, oct 2003.

11. Leïla Staali, Matthias Mörgelin, Lars Björck, and Hans Tapper. Streptococcus pyogenes expressing $\mathrm{m}$ and $\mathrm{m}$-like surface proteins are phagocytosed but survive inside human neutrophils. Cellular Microbiology, 5(4):253-265, apr 2003.

12. Ulrich von Pawel-Rammingen, Björn $P$ Johansson, and Lars Björck. IdeS, a novel streptococcal cysteine proteinase with unique specificity for immunoglobulin g. The EMBO Journal, 21(7):1607-1615, apr 2002.

13. M Collin and A Olsén. EndoS, a novel secreted protein from streptococcus pyogenes with endoglycosidase activity on human IgG. The EMBO Journal, 20(12):3046-3055, jun 2001.

14. P, K H Schmidt, J Cooney, and L Björck. M1 protein and protein h: IgGFc- and albuminbinding streptococcal surface proteins encoded by adjacent genes. The Biochemical Journal, 300 ( Pt 3):877-886, jun 1994.

15. Partho Ghosh. Variation, indispensability, and masking in the $\mathrm{m}$ protein. Trends in Microbiology, 26(2):132-144, 2018.

16. Lotta Happonen, Simon Hauri, Gabriel Svensson Birkedal, Christofer Karlsson, Therese de Neergaard, Hamed Khakzad, Pontus Nordenfelt, Mats Wikström, Magdalena Wisniewska, Lars Björck, Lars Malmström, and Johan Malmström. A quantitative streptococcus pyogenes-human protein-protein interaction map reveals localization of opsonizing antibodies. Nature Communications, 10(1):2727, jun 2019.

17. Pauline Macheboeuf, Cosmo Buffalo, Chi-yu Fu, Annelies S Zinkernagel, Jason N Cole, John E Johnson, Victor Nizet, and Partho Ghosh. Streptococcal $m 1$ protein constructs a pathological host fibrinogen network. Nature, 472(7341):64-68, apr 2011.

18. Heiko Herwald, Henning Cramer, Matthias Mörgelin, Wayne Russell, Ulla Sollenberg, Anna Norrby-Teglund, Hans Flodgaard, Lennart Lindbom, and Lars Björck. M protein, a classi- 
bioRxiv preprint doi: https://doi.org/10.1101/2021.03.01.433494; this version posted March 19, 2021. The copyright holder for this preprint (which was not certified by peer review) is the author/funder, who has granted bioRxiv a license to display the preprint in perpetuity. It is made available under aCC-BY-NC-ND 4.0 International license.

cal bacterial virulence determinant, forms complexes with fibrinogen that induce vascular leakage. Cell, 116(3):367-379, feb 2004

19. Fredric Carlsson, Charlotta Sandin, and Gunnar Lindahl. Human fibrinogen bound to streptococcus pyogenes $\mathrm{m}$ protein inhibits complement deposition via the classical pathway. Molecular Microbiology, 56(1):28-39, apr 2005.

20. Maria Weineisen, Ulf Sjöbring, Maria Fällman, and Tommy Andersson. Streptococcal m5 protein prevents neutrophil phagocytosis by interfering with $\mathrm{CD} 11 \mathrm{~b} / \mathrm{CD} 18$ receptor-mediated association and signaling. Journal of Immunology, 172(6):3798-3807, mar 2004.

21. Pontus Nordenfelt, Sofia Waldemarson, Adam Linder, Matthias Mörgelin, Christofer Karlsson, Johan Malmström, and Lars Björck. Antibody orientation at bacterial surfaces is related to invasive infection. The Journal of Experimental Medicine, 209(13):2367-2381, dec 2012.

22. Manisha Pandey, Victoria Ozberk, Ainslie Calcutt, Emma Langshaw, Jessica Powell, Tania Rivera-Hernandez, Mei-Fong Ho, Zachary Philips, Michael R Batzloff, and Michael F Good. Streptococcal immunity is constrained by lack of immunological memory following a single episode of pyoderma. PLoS Pathogens, 12(12):e1006122, dec 2016.

23. Michael P Motley, Kasturi Banerjee, and Bettina C Fries. Monoclonal antibody-based therapies for bacterial infections. Current Opinion in Infectious Diseases, 32(3):210-216, 2019.

24. James B Dale and Mark J Walker. Update on group a streptococcal vaccine development. Current Opinion in Infectious Diseases, apr 2020.

25. Armira Azuar, Wanli Jin, Saori Mukaida, Waleed M Hussein, Istvan Toth, and Mariusz Skwarczynski. Recent advances in the development of peptide vaccines and their delivery systems against group a streptococcus. Vaccines, 7(3), jul 2019.

26. Gunnar Lindahl. Subdominance in antibody responses: implications for vaccine development. Microbiology and Molecular Biology Reviews, 85(1), nov 2020.

27. Victoria Ozberk, Manisha Pandey, and Michael F Good. Contribution of cryptic epitopes in designing a group a streptococcal vaccine. Human vaccines \& immunotherapeutics, 14(8):2034-2052, jun 2018.

28. Sameer S Kadri, Bruce J Swihart, Stephanie L Bonne, Samuel F Hohmann, Laura V Hennessy, Peter Louras, Heather L Evans, Chanu Rhee, Anthony F Suffredini, David C Hooper, Dean A Follmann, Eileen M Bulger, and Robert L Danner. Impact of intravenous immunoglobulin on survival in necrotizing fasciitis with vasopressor-dependent shock: A propensity score-matched analysis from 130 US hospitals. Clinical Infectious Diseases, 64(7):877-885, apr 2017.

29. Anna Linnér, Jessica Darenberg, Jan Sjölin, Birgitta Henriques-Normark, and Anna NorrbyTeglund. Clinical efficacy of polyspecific intravenous immunoglobulin therapy in patients with streptococcal toxic shock syndrome: a comparative observational study. Clinical Infectious Diseases, 59(6):851-857, sep 2014

30. Martin B Madsen, Peter B Hjortrup, Marco B Hansen, Theis Lange, Anna Norrby-Teglund, Ole Hyldegaard, and Anders Perner. Immunoglobulin $g$ for patients with necrotising soft tissue infection (INSTINCT): a randomised, blinded, placebo-controlled trial. Intensive Care Medicine, 43(11):1585-1593, nov 2017.

31. Tom Parks, Clare Wilson, Nigel Curtis, Anna Norrby-Teglund, and Shiranee Sriskandan. Polyspecific intravenous immunoglobulin in clindamycin-treated patients with streptococcal toxic shock syndrome: A systematic review and meta-analysis. Clinical Infectious Diseases, 67(9):1434-1436, oct 2018

32. Dennis R Burton and Lars Hangartner. Broadly neutralizing antibodies to HIV and their role in vaccine design. Annual Review of Immunology, 34:635-659, may 2016.

33. E Mitsi, A M Roche, J Reiné, T Zangari, J T Owugha, S H Pennington, J F Gritzfeld, A D Wright, A M Collins, S van Selm, M I de Jonge, S B Gordon, J N Weiser, and D M Ferreira. Agglutination by anti-capsular polysaccharide antibody is associated with protection against experimental human pneumococcal carriage. Mucosal Immunology, 10(2):385-394, 2017.

34. Kathrin Moor, Médéric Diard, Mikael E Sellin, Boas Felmy, Sandra Y Wotzka, Albulena Toska, Erik Bakkeren, Markus Arnoldini, Florence Bansept, Alma Dal Co, Tom Völler, Andrea Minola, Blanca Fernandez-Rodriguez, Gloria Agatic, Sonia Barbieri, Luca Piccoli, Costanza Casiraghi, Davide Corti, Antonio Lanzavecchia, Roland R Regoes, Claude Loverdo, Roman Stocker, Douglas R Brumley, Wolf-Dietrich Hardt, and Emma Slack. Highavidity IgA protects the intestine by enchaining growing bacteria. Nature, 544(7651):498502, apr 2017

35. I M Frick, M Mörgelin, and L Björck. Virulent aggregates of streptococcus pyogenes are generated by homophilic protein-protein interactions. Molecular Microbiology, 37(5):12321247 , sep 2000.

36. Stylianos Bournazos, Taia T Wang, Rony Dahan, Jad Maamary, and Jeffrey V Ravetch. Signaling by antibodies: recent progress. Annual Review of Immunology, 35:285-311, apr 2017.

37. Pontus Nordenfelt and Hans Tapper. Phagosome dynamics during phagocytosis by neutrophils. Journal of Leukocyte Biology, 90(2):271-284, aug 2011.

38. Therese de Neergaard, Martin Sundwall, Sebastian Wrighton, and Pontus Nordenfelt. Highsensitivity assessment of phagocytosis by persistent association-based normalization. Journal of Immunology, 206(1):214-224, jan 2021.

39. Shiranee Sriskandan, Melissa Ferguson, Victoria Elliot, Lee Faulkner, and Jonathan Cohen Human intravenous immunoglobulin for experimental streptococcal toxic shock: bacterial clearance and modulation of inflammation. The Journal of Antimicrobial Chemotherapy, 58(1):117-124, jul 2006

40. Simon Hauri, Hamed Khakzad, Lotta Happonen, Johan Teleman, Johan Malmström, and Lars Malmström. Rapid determination of quaternary protein structures in complex biological samples. Nature Communications, 10(1):192, jan 2019.

41. Vibha Kumra Ahnlide, Therese de Neergaard, Martin Sundwall, Tobias Ambjörnsson, and Pontus Nordenfelt. A predictive model of antibody binding in the presence of IgG-interacting bacterial surface proteins. BioRxiv, oct 2020.

42. Christian Spoerry, Pontus Hessle, Melanie J Lewis, Lois Paton, Jenny M Woof, and Ulrich von Pawel-Rammingen. Novel IgG-degrading enzymes of the IgdE protease family link substrate specificity to host tropism of streptococcus species. Plos One, 11(10):e0164809, oct 2016

43. K F Jones and V A Fischetti. The importance of the location of antibody binding on the $\mathrm{m} 6$ protein for opsonization and phagocytosis of group a $\mathrm{m} 6$ streptococci. The Journal of Experimental Medicine, 167(3):1114-1123, mar 1988.
44. Jonas Lannerg, Mattias C U Gustafsson, Johan Waldemarsson, Anna Norrby-Teglund, Margaretha St-Carlemalm, and Gunnar Lindahl. The hypervariable region of streptococcus pyogenes $\mathrm{m}$ protein escapes antibody attack by antigenic variation and weak immunogenicity. Cell Host \& Microbe, 10(2):147-157, aug 2011.

45. Joel A Swanson. Shaping cups into phagosomes and macropinosomes. Nature Reviews. Molecular Cell Biology, 9(8):639-649, aug 2008.

46. P Sondermann, R Huber, V Oosthuizen, and U Jacob. The 3.2-a crystal structure of the human IgG1 fc fragment-fc gammaRIII complex. Nature, 406(6793):267-273, jul 2000.

47. Andrew B Herr, Edward R Ballister, and Pamela J Bjorkman. Insights into IgA-mediated immune responses from the crystal structures of human FcalphaRI and its complex with IgA1-fc. Nature, 423(6940):614-620, jun 2003

48. Matthew H Bakalar, Aaron M Joffe, Eva M Schmid, Sungmin Son, Marija Podolski, and Daniel A Fletcher. Size-dependent segregation controls macrophage phagocytosis of antibody-opsonized targets. Cell, 174(1):131-142.e13, jun 2018.

49. Spencer A Freeman, Anthony Vega, Magdalena Riedl, Richard F Collins, Phillip P Ostrowski, Elliot C Woods, Carolyn R Bertozzi, Markku I Tammi, Diane S Lidke, Pauline Johnson, Satyajit Mayor, Khuloud Jaqaman, and Sergio Grinstein. Transmembrane pickets connect cyto- and pericellular skeletons forming barriers to receptor engagement. Cell, 172(1-2):305-317.e10, jan 2018.

50. Alexia Kanyavuz, Annaelle Marey-Jarossay, Sébastien Lacroix-Desmazes, and Jordan D Dimitrov. Breaking the law: unconventional strategies for antibody diversification. Nature Reviews. Immunology, 19(6):355-368, 2019

51. A Trkola, M Purtscher, T Muster, C Ballaun, A Buchacher, N Sullivan, K Srinivasan, J Sodroski, J P Moore, and $\mathrm{H}$ Katinger. Human monoclonal antibody $2 \mathrm{G} 12$ defines a distinctive neutralization epitope on the gp120 glycoprotein of human immunodeficiency virus type 1 . Journal of Virology, 70(2):1100-1108, feb 1996.

52. Johannes S Gach, Paul G Furtmüller, Heribert Quendler, Paul Messner, Ralf Wagner, Hermann Katinger, and Renate Kunert. Proline is not uniquely capable of providing the pivot point for domain swapping in 2G12, a broadly neutralizing antibody against HIV-1. The Journal of Biological Chemistry, 285(2):1122-1127, jan 2010.

53. Daniel A Calarese, Hing-Ken Lee, Cheng-Yuan Huang, Michael D Best, Rena D Astronomo, Robyn L Stanfield, Hermann Katinger, Dennis R Burton, Chi-Huey Wong, and lan A Wilson. Dissection of the carbohydrate specificity of the broadly neutralizing anti-HIV-1 antibody 2G12. Proceedings of the National Academy of Sciences of the United States of America, 102(38):13372-13377, sep 2005

54. Leopold Kong, Robyn L. Stanfield, and lan A. Wilson. Molecular recognition of HIV glycans by antibodies. In Ralph Pantophlet, editor, HIV glycans in infection and immunity, pages 117-141. Springer New York, New York, NY, 2014.

55. Roland E Kontermann and Ulrich Brinkmann. Bispecific antibodies. Drug Discovery Today, 20(7):838-847, jul 2015.

56. Takamitsu Hattori, Darson Lai, Irina S Dementieva, Sherwin P Montaño, Kohei Kurosawa, Yupeng Zheng, Louesa R Akin, Kalina M Świst Rosowska, Adrian T Grzybowski, Akiko Koide, Krzysztof Krajewski, Brian D Strahl, Neil L Kelleher, Alexander J Ruthenburg, and Shohei Koide. Antigen clasping by two antigen-binding sites of an exceptionally specific antibody for histone methylation. Proceedings of the National Academy of Sciences of the United States of America, 113(8):2092-2097, feb 2016.

57. Jane Oliver, Erandi Malliya Wadu, Nevil Pierse, Nicole J Moreland, Deborah A Williamson, and Michael G Baker. Group a streptococcus pharyngitis and pharyngeal carriage: A metaanalysis. PLoS Neglected Tropical Diseases, 12(3):e0006335, mar 2018.

58. Kimberly A Kline, Stefan Fälker, Sofia Dahlberg, Staffan Normark, and Birgitta HenriquesNormark. Bacterial adhesins in host-microbe interactions. Cell Host \& Microbe, 5(6):580592, jun 2009

59. Mariusz Skwarczynski and Istvan Toth. Peptide-based synthetic vaccines. Chemical science (Royal Society of Chemistry : 2010), 7(2):842-854, feb 2016.

60. Kenneth Smith, Lori Garman, Jens Wrammert, Nai-Ying Zheng, J Donald Capra, Rafi Ahmed, and Patrick C Wilson. Rapid generation of fully human monoclonal antibodies specific to a vaccinating antigen. Nature Protocols, 4(3):372-384, 2009

61. M Collin and A Olsén. Generation of a mature streptococcal cysteine proteinase is dependent on cell wall-anchored m1 protein. Molecular Microbiology, 36(6):1306-1318, jun 2000.

62. T Cedervall, P, L Stenberg, A Herrmann, and B öm. Allosteric and temperature effects on the plasma protein binding by streptococcal $\mathrm{m}$ protein family members. Scandinavian Journal of Immunology, 42(4):433-441, oct 1995.

63. P , J Cooney, F Kishimoto, and L Björck. Protein h-a novel lgG binding bacterial protein. Molecular Immunology, 27(6):523-531, jun 1990

64. Vibha Kumra Ahnlide, Therese de Neergaard, Martin Sundwall, Tobias Ambjörnsson, and Pontus Nordenfelt. A predictive model of antibody binding in the presence of IgG-interacting bacterial surface proteins. BioRxiv, oct 2020

65. Julia Koehler Leman, Brian D Weitzner, Steven M Lewis, RosettaCommons Consortium, and Richard Bonneau. Macromolecular modeling and design in rosetta: new methods and frameworks. apr 2019.

66. Brian D Weitzner, Jeliazko R Jeliazkov, Sergey Lyskov, Nicholas Marze, Daisuke Kuroda, Rahel Frick, Jared Adolf-Bryfogle, Naireeta Biswas, Roland L Dunbrack, and Jeffrey J Gray. Modeling and docking of antibody structures with rosetta. Nature Protocols, 12(2):401-416, jan 2017.

67. Yifan Song, Frank DiMaio, Ray Yu-Ruei Wang, David Kim, Chris Miles, Tj Brunette, James Thompson, and David Baker. High-resolution comparative modeling with RosettaCM. Structure, 21(10):1735-1742, oct 2013

68. Yumeng Yan, Huanyu Tao, and Sheng-You Huang. HSYMDOCK: a docking web server for predicting the structure of protein homo-oligomers with $\mathrm{cn}$ or dn symmetry. Nucleic Acids Research, 46(W1):W423-W431, jul 2018.

69. Yasaman Karami, Julien Rey, Guillaume Postic, Samuel Murail, Pierre Tufféry, and Sjoerd $J$ de Vries. DaReUS-loop: a web server to model multiple loops in homology models. Nucleic Acids Research, 47(W1):W423-W428, jul 2019.

70. Jeffrey J Gray. High-resolution protein-protein docking. Current Opinion in Structural Biology, 16(2):183-193, apr 2006. 